\title{
Comments on Liquid Hydrogen Absorbers for MICE
}

\author{
Michael A. Green \\ Lawrence Berkeley National Laboratory
}

\section{Introduction}

The Muon Ionization Cooling Experiment (MICE) consists of superconducting solenoid magnets, RF cavities, and absorbers to reduce the momentum of a muon beam passing through them. The layout of the experiment is shown in Figure 1. Three liquid hydrogen absorbers are shown inside the focusing solenoids for MICE. The longitudinal thickness of the absorbers must reduce the muon momentum by about $20 \mathrm{MeV} / \mathrm{c}$ in each absorber. Longitudinal momentum that is removed from the muon by the absorbers is put back into the muon beam by acceleration from the RF cavities. This report discusses some thoughts of the author concerning liquid cryogen absorbers to be used in MICE. The type of absorber that is discussed in this report is an absorber that cools the hydrogen in the absorber through natural convection from the walls of the absorber that are cooled by helium gas entering at $14 \mathrm{~K}$.



Figure 1. A General Layout of the Full MICE Experiment Showing all of the Superconducting Solenoids, the RF Cavities, the Liquid Hydrogen Absorbers, the Central Trackers in a Uniform Magnetic Field and Other Types of Detectors 
The following topics will be discussed in this report; 1) the path for the heat from various sources that come into the absorber, 2) some absorber hydrogen safety issues, 3) the type of heat exchanger used to exchange the heat from the hydrogen in the absorber to the helium flowing through passages in the walls, 4) the effect of substituting liquid helium for liquid hydrogen in the absorber, 5) piping issues within the absorber and magnet cryostat, 6) methods for achieving variable liquid absorber thickness, and 7) absorber and magnet integration issues.

As part of the discussion concerning heat exchangers for absorbers cooled by natural convection, will be an absorber with a separate heat exchanger that will have hydrogen driven through it by natural convection rather than by pumping with a separate pump. Two issues that will not be talked about in this report include window design and solid absorbers. The design criteria for absorber windows have been covered very well in various presentations concerning the liquid hydrogen absorbers. The absorber window may be the issue that is best understood. The topic of solid absorbers will be discussed in a future report. Solid absorbers have different heat transfer and integration issues from liquid absorbers.

Figure 2 shows some of the experimental steps envisioned for MICE between 2004 and 2007 (based on an optimistic scenario for the experiment). The first liquid hydrogen absorber and focusing magnet combination is not expected until the spring of 2006. The second absorber and focusing coil pair can appear as early as the fall of 2006. All three absorbers won't appear until the middle of 2007.

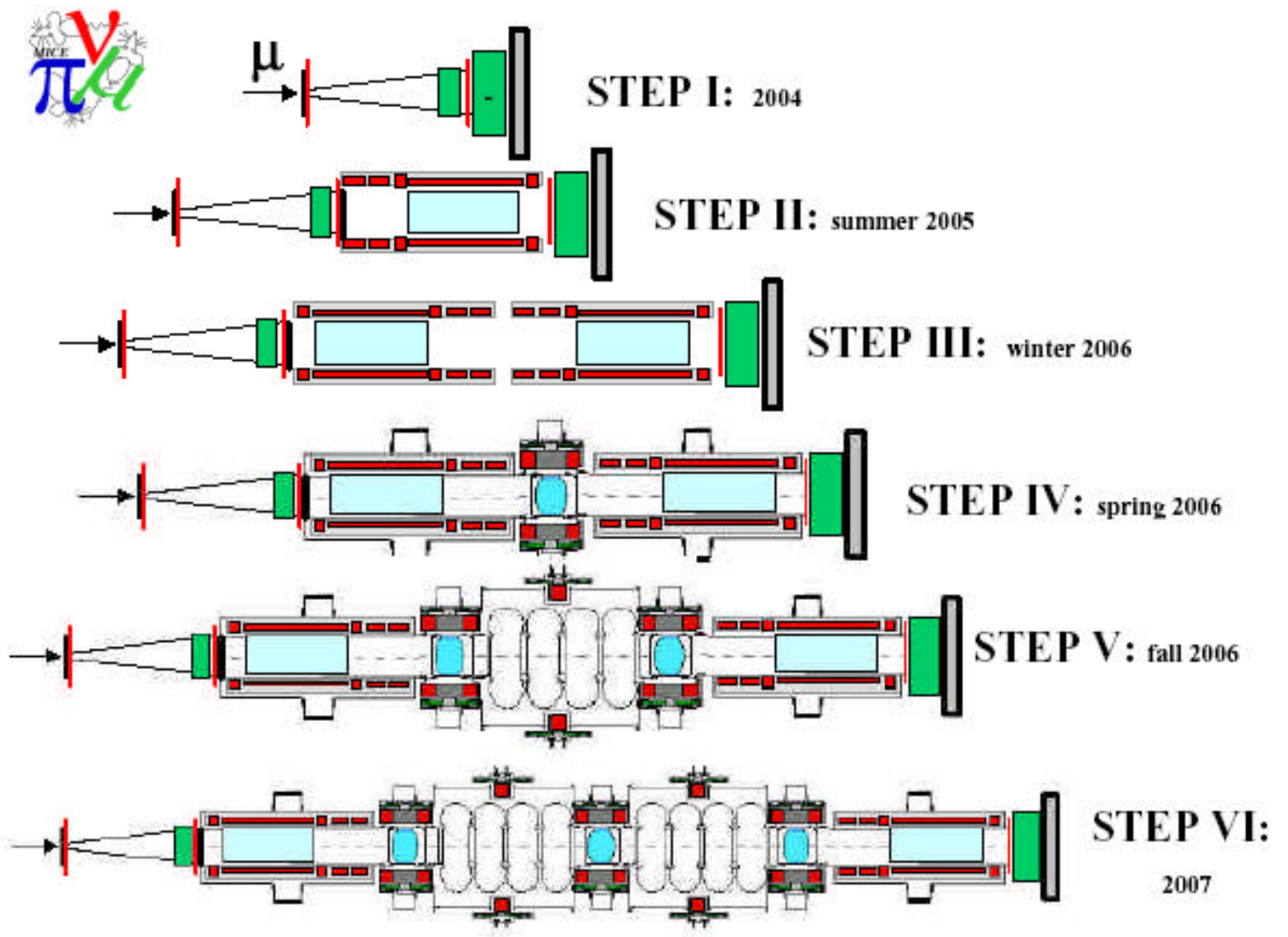

Figure 2. An Illustration of Six Operating Steps Proposed for MICE. These steps show the need for building the solenoids in modular units. Three types of solenoid units can be used to assemble the steps shown in this figure. 


\section{An Absorber Focusing Coil Combination for the Case Study}

Figures 3 and 4 show cross-sections of the focusing magnet and the liquid hydrogen (or liquid helium) absorber. The absorber shown has $19 \mathrm{~K}$ hydrogen windows that are $350 \mathrm{~mm}$ in diameter. Safety windows that are at $70 \mathrm{~K}$ are also shown. The space between the hydrogen window and the safety window is under vacuum. This vacuum is connected to a large vacuum chamber that is outside of the experimental hall. (See Figure 5 for a hydrogen absorber safety system.) All surfaces exposed to the $\mathrm{RF}$ cavity vacuum are at a temperature of at least $55 \mathrm{~K}$ to prevent air from freezing on these surfaces.

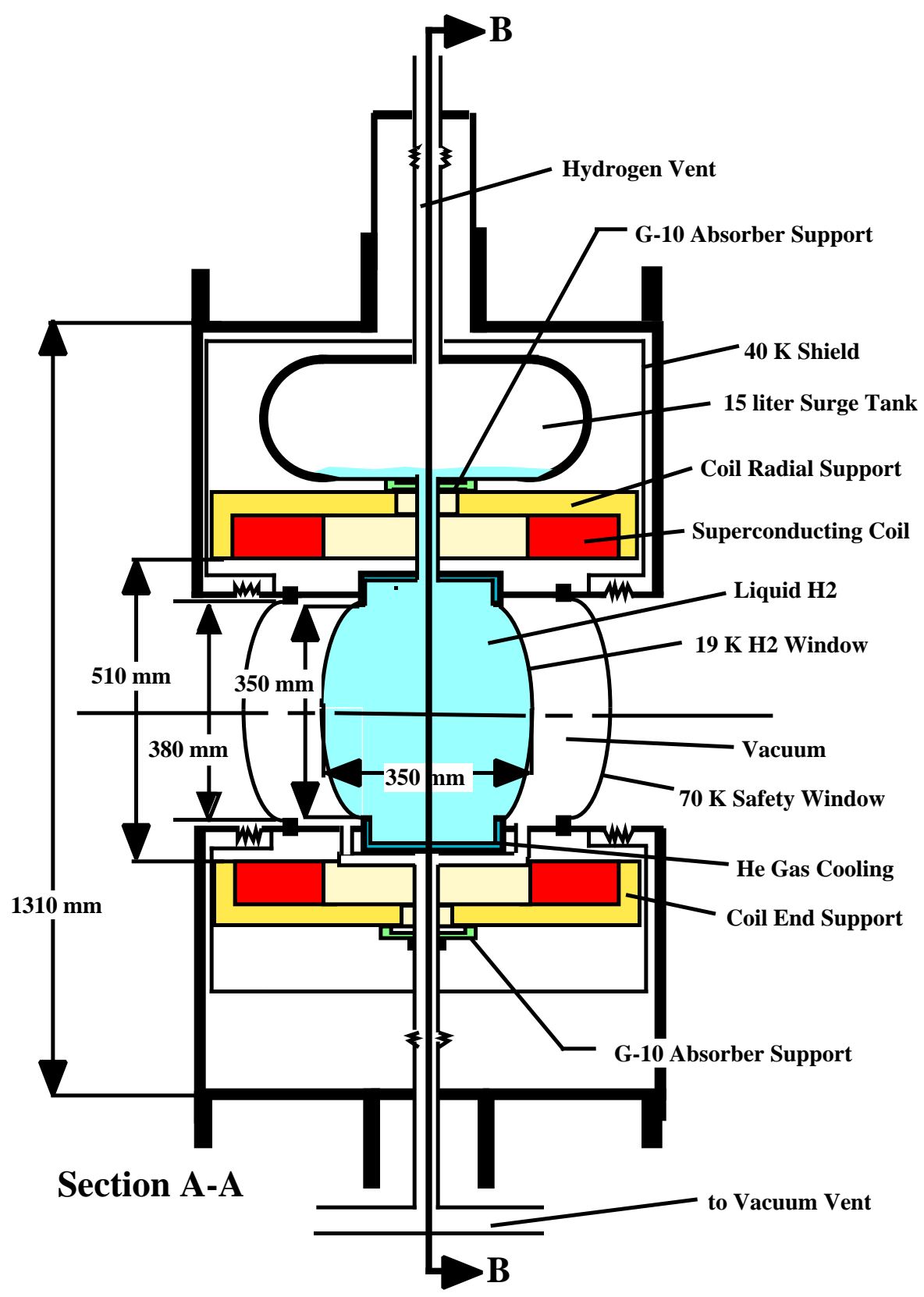

Figure 3. An Absorber and Focusing Coil Cross-section that lies on the Focusing Solenoid Axis of Rotation 


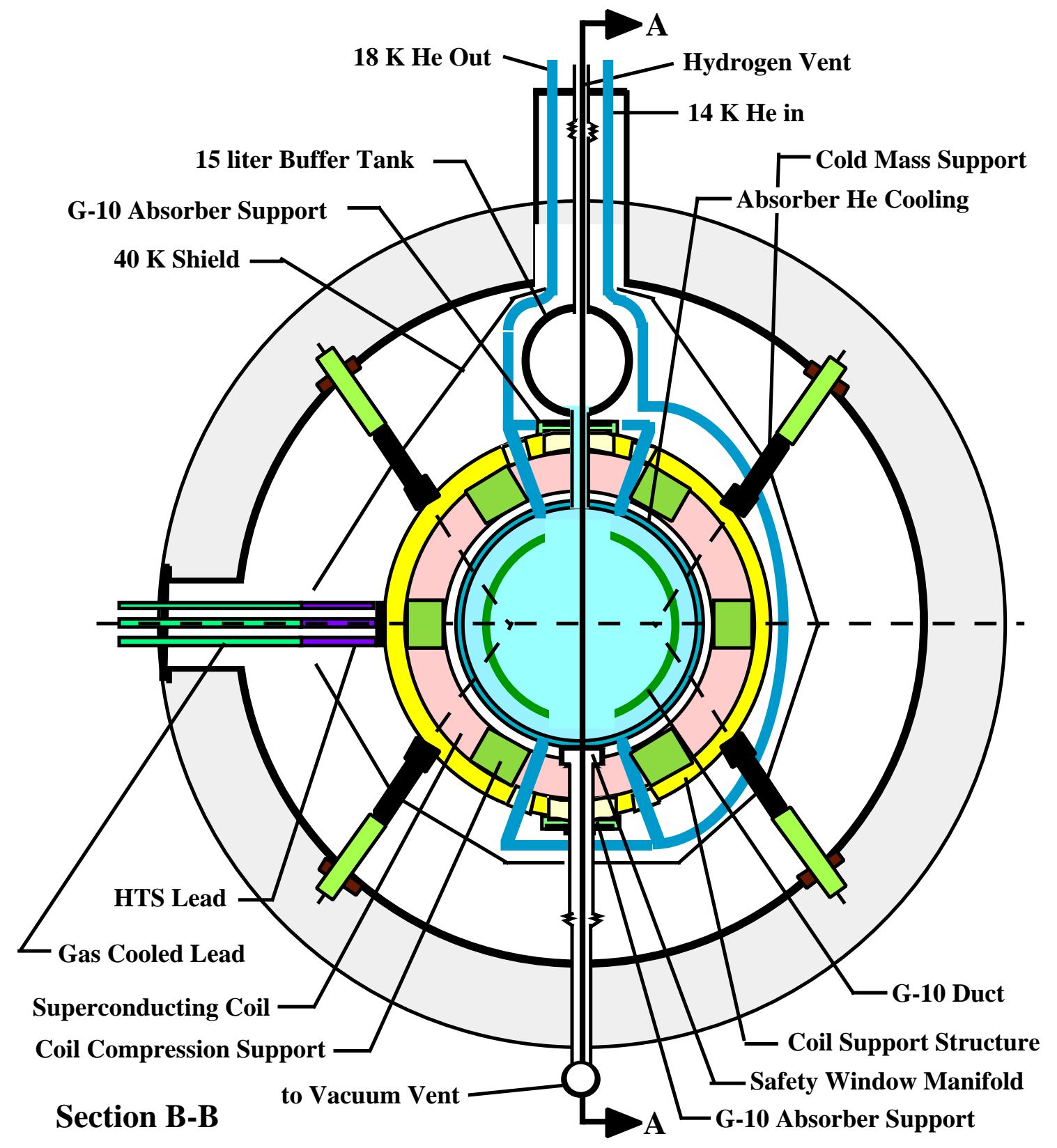

Figure 4. A Cross-section of the Absorber that is Perpendicular to the Focusing Solenoid Axis of Rotation

The surge tank shown in Figures 3 and 4 allows for a rapid change in the absorber length. This tank is not needed if one can displace the cryogen in the absorber slowly to avoid boiling large amounts of liquid hydrogen (or helium) during the change of absorber length. Figure 4 shows $14 \mathrm{~K}$ helium entering the absorber body at the bottom. Helium at 15 to $18 \mathrm{~K}$ leaves the absorber body at the top. Since the cooled liquid hydrogen slides down the absorber wall due to its greater density (than the hydrogen at the center of the absorber), a counter-flow heat exchanger between the cold helium gas and the sub-cooled liquid hydrogen is formed. A duct inside the absorber wall is shown in Figure 4. This duct directs the flow and prevents mixing of the warm rising hydrogen with the cold falling hydrogen. 


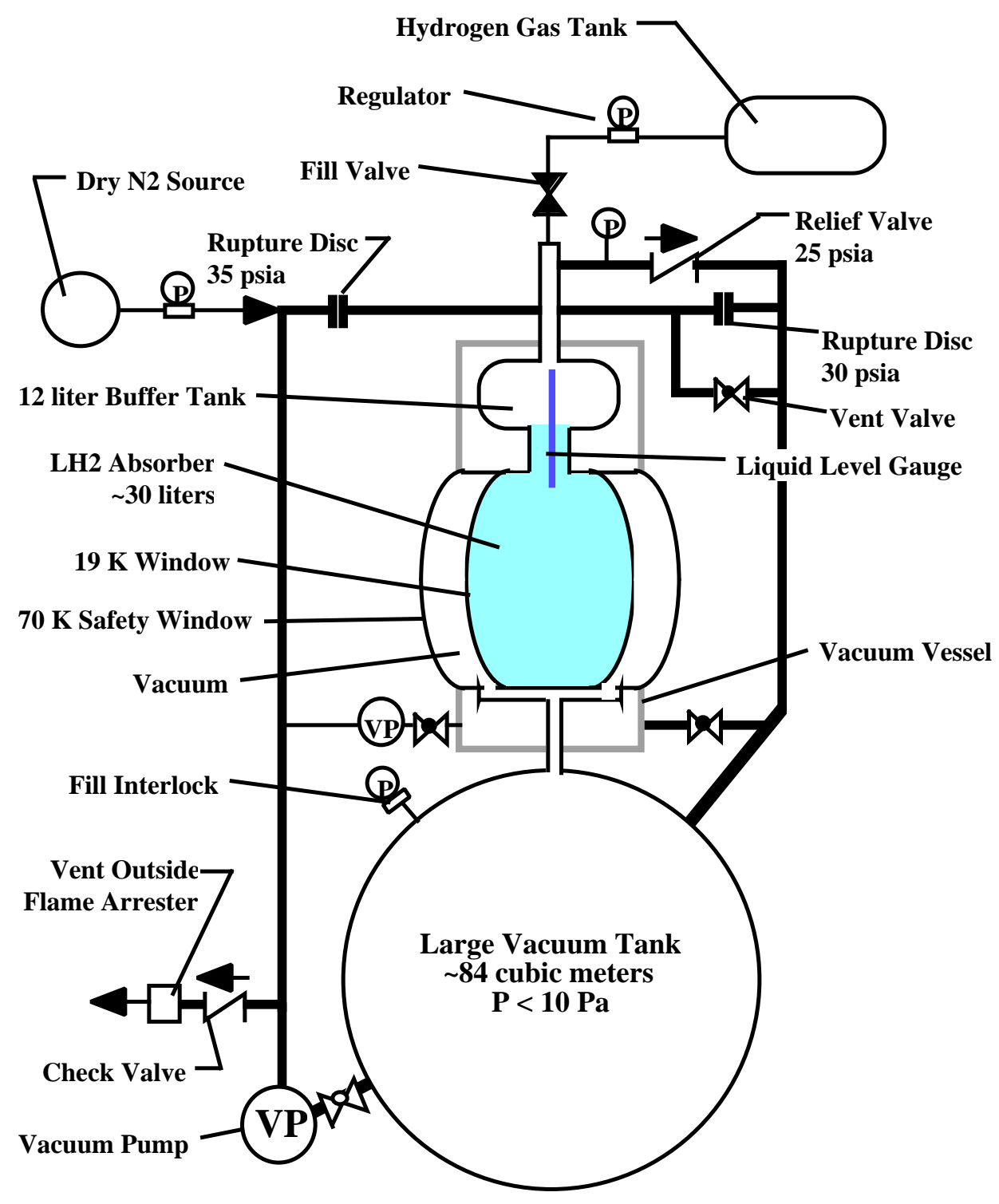

Figure 5. The Hydrogen Flow System and Hydrogen Vent Safety System for a Liquid Hydrogen Absorber

Figure 5 shows the absorber and its hydrogen handling system. As the absorber is cooled by helium gas entering at $14 \mathrm{~K}$, hydrogen at 1 bar is condensed on the wall as long as the absorber wall temperature is less than $20 \mathrm{~K}$. Once the absorber is filled with liquid hydrogen; the fill valve is closed. The pressure in the absorber falls to the saturation pressure for the liquid hydrogen in the absorber.

The average temperature and pressure in the absorber is determined by the heat flow into the hydrogen in the absorber and the mass flow of the helium flowing through the absorber body. The design heat flow into the liquid hydrogen in the absorber is about $100 \mathrm{~W}$ for MICE. When the absorber is filled with liquid helium, the design heat load into the liquid helium is about $12 \mathrm{~W}$. If the absorber is properly designed, most of the heat flowing into the absorber safety windows and the heat conducted into the absorber body from room temperature will be taken into the $14 \mathrm{~K}$ helium stream directly without that heat being transferred into the absorber cryogen first. 


\section{The Heat Sources and Heat Paths for the MICE Liquid Absorber}

The heat into the absorber comes from four sources. The first source is heat conduction $\mathrm{Q}_{\mathrm{C}}$ from room temperature $(300 \mathrm{~K})$ to the absorber through stainless steel walls that connect the absorber to the absorber cryostat vacuum vessel. The second source is thermal radiation $\mathrm{Q}_{\mathrm{R}}$ from the room temperature $\mathrm{RF}$ cavity to the outer absorber window. The third source is beam-heating $\mathrm{Q}_{\mathrm{B}}$ that is deposited in the liquid cryogen inside the absorber. This heat includes energy absorbed from the muons and energy absorbed from the dark currents and x-rays produced by the adjacent RF cavities. The fourth source of heat to the absorber is heat from a resistive heater $\mathrm{Q}_{\mathrm{H}}$ that may be used to start and maintain the natural convection in the absorber. The total heat that goes into the absorber $\mathrm{Q}_{\mathrm{T}}$ can be shown as follows;

$$
Q_{T}=Q_{C}+Q_{R}+Q_{B}+Q_{H}
$$

For MICE, the design $\mathrm{Q}_{\mathrm{T}}$ for liquid hydrogen is about $100 \mathrm{~W}$. When liquid helium is in the absorber, $\mathrm{Q}_{\mathrm{T}}$ is about $35 \mathrm{~W}$. The total heat flow into the absorber $\mathrm{Q}_{\mathrm{T}}$ ends up in the helium stream that cools the absorber body. Figure 6 shows that the total heat flow enters the absorber body through two distinct routes, by conduction into the absorber body directly and by convection heat transfer from the cryogenic fluid in the absorber to the absorber body. The heat that enters the solid absorber body is transferred to the helium in the cooling channel through forced convection heat transfer to the flowing helium.



Figure 6. Heat Flow Paths into the Liquid Cryogen Absorber. Note: $\mathrm{Q}_{C}$ and $\mathrm{Q}_{\mathrm{R}}$ flow directly to the absorber body. $\mathrm{Q}_{\mathrm{B}}$ and $\mathrm{Q}_{\mathrm{H}}$ flow into the absorber body via the energy absorbing liquid in the absorber body. 


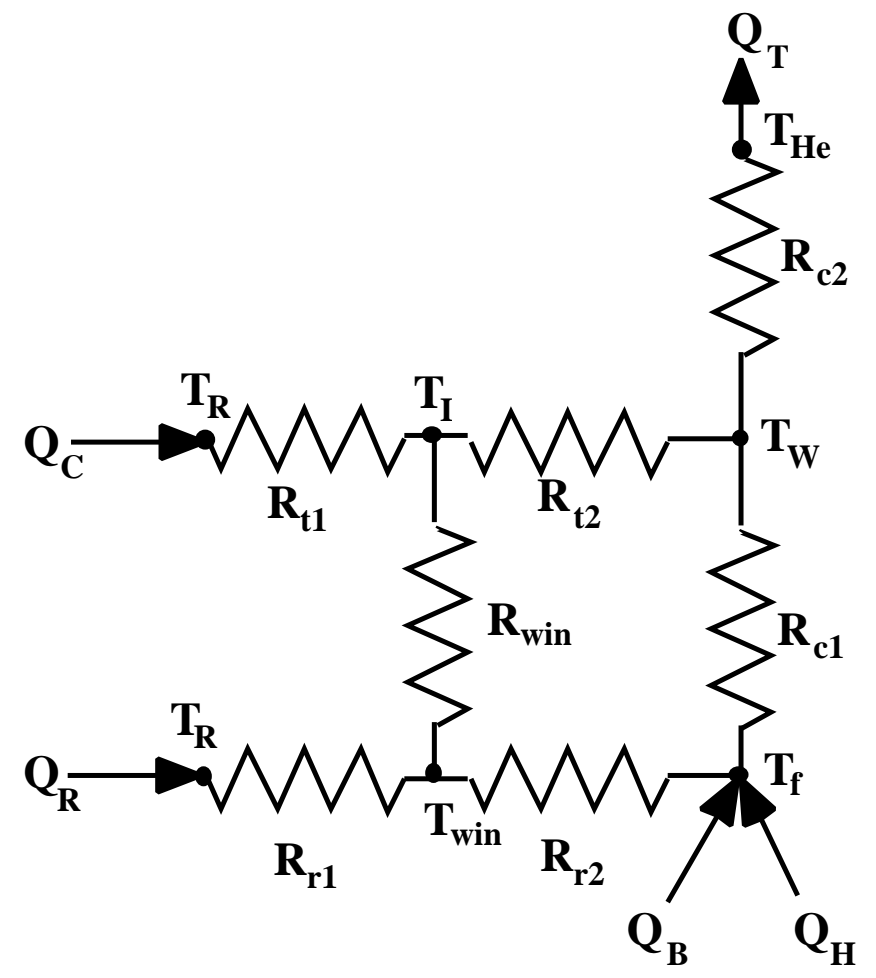

Figure 7. A Simplified Electrical Circuit Analogy for Heat Transfer to the Helium Cooling Stream through the Absorber

The heat transfer into and through the cryogenic absorber can be represented by an analog electric circuit such as that shown in Figure 7 [1],[2]. Ohms law says that E = IR. The thermal analog of ohms law is the expression $\Delta \mathrm{T}=\mathrm{QR}$, where $\Delta \mathrm{T}(\mathrm{K})$ is the temperature difference driving a thermal current $\mathrm{Q}$ (W) across a heat resistance $R\left(\mathrm{KW}^{-1}\right)$. The values of heat flow $\mathrm{Q}_{\mathrm{C}}, \mathrm{Q}_{\mathrm{R}}, \mathrm{Q}_{\mathrm{B}}, \mathrm{Q}_{\mathrm{H}}$ and $\mathrm{Q}_{\mathrm{T}}$ are defined as they are for equation 1. The heat flows shown in Figure 6 and 7 are the same as those defined in equation 1. Unlike a typical electrical circuit, the resistances in Figure 7 are temperature dependent. $R_{r 1}$ and $\mathrm{R}_{\mathrm{r} 2}$ represent effective resistances for radiation heat transfer and thus are strongly dependent on the temperature $T_{R}$ and $T_{\text {win }}$. The other thermal resistances are not so strongly temperature dependent. Because the thermal resistances are temperature dependent, the temperatures calculated for network shown in Figure 7 must be calculated iteratively.

For the absorber shown in Figures 3 and 4 we can do a first estimate of the temperatures in the network shown in Figure 7. $\mathrm{T}_{\mathrm{R}}=300 \mathrm{~K}$, which is room temperature. $\mathrm{T}_{\mathrm{He}}$ is from 14 to $18 \mathrm{~K}$, which is the allowable temperature range for the helium flow stream. $\mathrm{T}_{\mathrm{I}}$ must be greater than $55 \mathrm{~K}$, in order to prevent oxygen from freezing on the vacuum window surface. $\mathrm{T}_{\mathrm{f}}$ can not be higher than $20.3 \mathrm{~K}$ and $\mathrm{T}_{\mathrm{W}}$ must be between $\mathrm{T}_{\mathrm{f}}$ and $\mathrm{T}_{\mathrm{He}}$. For all practical purposes, $\mathrm{T}_{\text {win }}$ is unlikely to be greater than $150 \mathrm{~K}$.

If one looks at the temperatures that are defined by the problem, one can come to a number of conclusions concerning the resistances one has to use in the thermal circuit. Some of the more important conclusions are: 1) The value of $\mathrm{R}_{\mathrm{t} 1}<6 \mathrm{R}_{\mathrm{t} 2}$ so that $\mathrm{T}_{\mathrm{I}}$ is greater than $55 \mathrm{~K}$ even when there is no radiation heat transfer to the window. 2) The value of $R_{r 2}>R_{r 1}$ because these values of the radiation 
heat transfer resistance have a $1 / \mathrm{T}^{3}$ term in them where $\mathrm{T}$ is the higher temperature in the radiation heat transfer equation. In other words, radiation heat-transfer between the vacuum window at an average temperature $\mathrm{T}_{\text {win }}$ that is less than $100 \mathrm{~K}$ and the cryogen window at $\mathrm{T}_{\mathrm{f}}$ can be neglected compared to conduction in the vacuum window itself. 3) The sum $\mathrm{R}_{\mathrm{c} 1}$ and $\mathrm{R}_{\mathrm{c} 2}$ must be less than $0.05 \mathrm{~K} \mathrm{~W}^{-1}$ because the absorber design calls for putting of the order of $100 \mathrm{~W}$ into the absorber and $\mathrm{T}_{\mathrm{f}}$ can not be much more than about $5 \mathrm{~K}$ above the average value of $\mathrm{T}_{\mathrm{He}}$. 4) It is desirable to minimize $\mathrm{Q}_{\mathrm{C}}$ and $\mathrm{Q}_{\mathrm{R}}$. Simply stated this means that the heat leaks from room temperature into the absorber are minimized. 5) Since the design value for $Q_{T}$ is about $100 \mathrm{~W}$, the design values of $Q_{B}+Q_{H}$ must be equal to or greater than $100-\left(\mathrm{Q}_{\mathrm{C}}+\mathrm{Q}_{\mathrm{R}}\right)$. The only thing that is not taken into consideration in the thermal circuit model is the heat transfer across the aluminum wall between the liquid cryogen in the absorber and the helium that is cooling the absorber in the absorber body. This thermal resistance of this wall must be small even when compared to $\mathrm{R}_{\mathrm{cl}}$ and $\mathrm{R}_{\mathrm{c} 2}$. The reader will see later in this report that is true for the liquid absorber that is proposed for MICE.

It is useful to calculate the values of the resistance in the network shown in Figure 7. Thermal resistances $R_{t 1}$ and $R_{t 2}$ are simple thermal conduction resistances, which take the following form;

$$
\begin{aligned}
& R_{t 1}=\frac{l_{t 1}}{k_{a 1} A_{t 1}} \\
& R_{t 2}=\frac{l_{t 2}}{k_{a 2} A_{t 2}}
\end{aligned}
$$

where $l_{t 1}$ is the length of thermal path between room temperature and the vacuum window; $1_{t 2}$ is the length of the thermal path between the vacuum window and the body of the absorber; $A_{t 1}$ is the average cross-section area of path $1_{t 1}$; and $A_{t 2}$ is the average cross-section area of path $1_{t 2}$. The value of $k_{a 1}$ is the average thermal conductivity along path $\mathrm{l}_{\mathrm{t} 1}$, and $\mathrm{k}_{\mathrm{a} 2}$ is the average thermal conductivity along path $\mathrm{l}_{\mathrm{t} 2}$.

The thermal conductivity varies greatly at cryogenic temperature, so determining the average value of the thermal conductivity along the path can be difficult. When one looks at the materials that are being used in the absorber assembly, the problem can be simplified. The 0.5-mm diameter tube connecting the outer window of the absorber to room temperature will be made from 304 stainless steel. It is proposed that the $0.7-\mathrm{mm}$ diameter tube that connects the outer window to the absorber body be made from 5456 aluminum. The windows themselves will be made from 6061-T6 aluminum or some similar alloy. All of these materials have a near constant electrical resistance over the temperature range of interest. All of these materials follow the Wiedeman and Franz law that relates electrical resistivity $\rho$ to thermal conductivity k. The general form for the Wiedeman and Franz law is given as follows;

$$
k \rho=L T
$$

where $\mathrm{L}$ is the Lorenz number $\left(\mathrm{L}=2.45 \times 10^{-8} \Omega \mathrm{W} \mathrm{K}^{-2}\right)$ and $\mathrm{T}$ is the absolute temperature. Since in the cases of interest, $\rho$ is constant $\mathrm{k}$ is linear with absolute temperature T. One then calculate the thermal conductivity integral $\Gamma(\mathrm{T})$ as a function of temperature $\mathrm{T}$ for the material and from that one can calculate 
the average thermal conductivity $\mathrm{k}_{\mathrm{a}}$ over the temperature range. For a material with constant resitivity $\rho$, the thermal conductivity integral takes the following form;

$$
\Gamma_{T 1 \rightarrow T 2}=\int_{T 1}^{T 2} k(T) d T=\frac{L}{2 \rho}\left[T_{2}^{2}-T_{1}^{2}\right]
$$

The average thermal conductivity $\mathrm{k}_{\mathrm{a}}$ over a member of constant cross-section has the following value;

$$
k_{a}=\frac{L}{2 \rho}\left[T_{2}+T_{1}\right]
$$

where $T_{1}$ and $T_{2}$ are the end point temperatures of a constant cross-section member that carries the heat.

Using Equation $4 b$, the values of $R_{t 1}$ and $R_{t 2}$ in equations $2 a$ and $2 b$ take the following form;

$$
R_{t 1}=\frac{2 \rho l_{t 1}}{L\left(T_{R}+T_{I}\right) A_{t 1}}
$$

and

$$
R_{t 2}=\frac{2 \rho l_{t 2}}{L\left(T_{I}+T_{W}\right) A_{t 2}}
$$

where $\rho_{\mathrm{c} 1}$ and $\rho_{\mathrm{c} 2}$ are the values of electrical resistivity for the materials in the thermal resistors $\mathrm{R}_{\mathrm{t} 1}$ and $\mathrm{R}_{\mathrm{t} 2}$ respectively as shown in Figure 7 .

The value of $\mathrm{R}_{\text {win }}$ for a circular window that is being hit with thermal radiation can be estimated using the following relationship;

$$
R_{w i n}=\frac{\rho}{2 \pi t_{w i n}\left(T_{I}+T_{w i n}\right) L}
$$

where $T_{I}$ and $T_{\text {win }}$ are defined in Figure 7 and $\rho$ is the electrical resistivity of the window material. The window is assumed to be a constant thickness window of thickness $t_{\text {win }}$. Other window configurations are more complicated.

The radiation heat transfer $\mathrm{Q}$ into and out of the vacuum windows can be calculated using the following equation;

$$
Q_{2 \rightarrow 1}=F_{2 \rightarrow 1} \varepsilon \sigma\left[T_{2}^{4}-T_{1}^{4}\right] A_{\text {win }}
$$

where $\mathrm{F}$ is the form factor between the two temperature regions. $\mathrm{F}$ will certainly be less than 1 , but given thermal reflection of surrounding walls $\mathrm{F}$ will not be much less than say 0.7. $\varepsilon$ is the thermal emissivity of the window surface, and $\sigma$ is the Stefan Bolzmann constant $\left(\sigma=5.67 \times 10^{-8} \mathrm{~W} \mathrm{~m}^{-2} \mathrm{~K}^{-4}\right)$. 
Since the vacuum window will be made from aluminum alloy, its emissivity can vary from 0.02 to 0.10 depending on the whether the surface is oxidized. $\mathrm{A}_{\text {win }}$ is the area of the window surface that is subject to thermal radiation. For our case, where the windows are $380 \mathrm{~mm}$ in diameter, the worst-case radiation heat leak from $\mathrm{T}_{\mathrm{R}}=300 \mathrm{~K}$ into both vacuum windows at $55 \mathrm{~K}$ (with $\mathrm{F}=1$ and $\varepsilon=0.1$ ) is about $10.4 \mathrm{~W}$.

Using equation 6 , one can estimate the thermal resistance $\mathrm{R}_{\mathrm{r} 1}$ and $\mathrm{R}_{\mathrm{r} 2}$ of the radiation heat transfer legs in the equivalent circuit shown in Figure 7.

$$
R_{r 1}=\frac{T_{R}-T_{w i n}}{F_{R \rightarrow \text { win }} \varepsilon \sigma\left[T_{R}^{4}-T_{w i n}^{4}\right] A_{w i n}}=\frac{0.85}{\varepsilon \sigma A_{w i n} T_{R}^{3}}
$$

and

$$
R_{r 2}=\frac{T_{\text {win }}-T_{f}}{F_{\text {win } \rightarrow f} \varepsilon \sigma\left[T_{\text {win }}^{4}-T_{f}^{4}\right] A_{\text {win }}}=\frac{0.85}{\varepsilon \sigma A_{\text {win }} T_{\text {win }}^{3}}
$$

Note: the important factor in both Equations $7 \mathrm{a}$ and $7 \mathrm{~b}$ is the highest temperature of the radiation heat transfer process. The value of the resistance is proportional to one over this temperature cubed. The heat transfer from the vacuum window to the cryogen window does not become an important factor unless the value of $\mathrm{R}_{\text {win }}$ approaches $\mathrm{R}_{\mathrm{r} 2}$. If $\mathrm{R}_{\text {win }}$ equals infinity (the window in infinitely thin so there is no heat flow in the radial direction in the window), then $R_{r 2}$ equals $R_{r 1}$ and the radiation heat flow to the cryogen window is half of the radiation heat transfer to the vacuum window if $R_{w i n}=0$. For our case the maximum possible heat flow to the cryogen windows can be no more than $5.2 \mathrm{~W}$ when $\mathrm{R}_{\mathrm{win}}=\infty$.

The resistance values $R_{c 1}$ and $R_{c 2}$ for the convective heat transfer in the absorber can be summarized with the following expressions;

$$
R_{c 1}=\frac{1}{h_{c 1} A_{1}}
$$

and

$$
R_{c 2}=\frac{1}{h_{c 2} A_{2}}
$$

where $h_{c 1}$ is the convection heat transfer coefficient between absorber fluid and the absorber wall; $A_{1}$ is the surface area of the heat exchanger wall on the absorber fluid side; $h_{c 2}$ is the convection heat transfer coefficient between the absorber wall and the helium in the cooling circuit; and $\mathrm{A}_{2}$ is heat exchange area of the helium cooling tubes in the absorber wall. In order to get the correct value for $R_{c 1}+R_{c 2}$, one must make sure that there is enough heat exchanger wall area $A_{1}$ and $A_{2}$ to allow the heat in the absorber fluid to be transferred to the helium cooling tube over the available temperature drop between the two stream. The second law of thermodynamics requires that $T_{f}>T_{w}>T_{H e}$. Since the temperature drop $T_{f}-T_{H e}$ across the absorber is about $5 \mathrm{~K}$ and $\mathrm{Q}$ design $=100 \mathrm{~W}, \mathrm{R}_{\mathrm{c} 1}+\mathrm{R}_{\mathrm{c} 2}$ can not be more than $0.05 \mathrm{KW}^{-1}$. 


\section{A Case Study for an Absorber with a Design $Q_{T}=100 \mathrm{~W}$ with $T_{\mathrm{f}} \leq 20 \mathrm{~K}$}

One can solve the network shown in Figure 7 iteratively by calculating the temperatures in the legs with the most heat flow first. The primary requirements are that the value of $\mathrm{T}_{\mathrm{f}}=20 \mathrm{~K}, \mathrm{~T}_{\mathrm{He}}=16 \mathrm{~K}$, and $\mathrm{T}_{\mathrm{R}}=300 \mathrm{~K}$. One calculates the flow by conduction into the absorber, and then one adds the heat flow due to radiation to the vacuum window. From that one gets a preliminary temperature map and a preliminary heat flow map. After a couple of iteration, one finds that about $70 \mathrm{~W}$ goes into the absorber fluid. That heat then into the helium. This means that $30 \mathrm{~W}$ is conducted into the absorber body and then into the helium without heating the absorber fluid. At the end of the final iteration, the various constants for the network are given below. The values of the leg resistances in the network are given in bold for the final iteration in Table 1. The heat exchange area $A_{c 1}$ and $A_{c 2}$ given in the table are reasonable assumptions for the absorber shown in Figures 3 and 4. The heat exchange surface can be extended from $0.22 \mathrm{~m}^{2}$ to the $0.44 \mathrm{~m}^{2}$ shown below by extending the surface using fins. There is a limit on how much the surface can be extended with fins, but increasing the area by a factor of two seems reasonable. The values of $h_{c 1}$ and $h_{c 2}$ are the ones that are required to take out a total of $100 \mathrm{~W}$ of out of the absorber (the design condition). If the heat transfer coefficients $h_{c 1}$ and $h_{c 2}$ can be increased, more that $100 \mathrm{~W}$ of total heat can be removed from the absorber. The calculation of the heat transfer coefficient $h_{\mathrm{c} 1}$ and $h_{\mathrm{c} 2}$ will explained in a later section of this report.

Table 1. Data needed to balance the Heat Flow in the Liquid Hydrogen Network shown in Figure 7

$$
\begin{array}{llll}
\mathrm{l}_{11}=0.15 \mathrm{~m} & \mathrm{~A}_{11}=0.0012 \mathrm{~m} 2 & \rho_{11}=4 \times 10^{-7} \Omega \mathrm{m} & \mathbf{R}_{11}=\mathbf{1 1 . 1} \mathbf{K ~ W}^{-1} \\
\mathrm{l}_{12}=0.10 \mathrm{~m} & \mathrm{~A}_{12}=0.0017 \mathrm{~m}^{2} & \rho_{12}=3.1 \times 10^{-8} \Omega \mathrm{m} & \mathbf{R}_{\mathbf{1 2}}=\mathbf{1 . 9 4} \mathbf{K ~ W}^{-1} \\
\mathrm{~T}_{\text {win }}=2 \times 10^{-4} \mathrm{~m} & & \rho_{\text {win }}=1.8 \times 10^{-8} \Omega \mathrm{m} & \mathbf{R}_{\text {win }}=\mathbf{3 . 6 6} \mathbf{K ~ W}^{-1} \\
\mathrm{e}=0.10 & \mathrm{~A}_{\text {win }}=0.22 \mathrm{~m}^{2} & & \mathbf{R}_{\mathrm{r} 1}=\mathbf{2 4 . 5} \mathbf{K ~ W}^{-1} \\
\mathrm{e}=0.10 & \mathrm{~A}_{\text {win }}=0.22 \mathrm{~m}^{2} & & \mathbf{R}_{\mathrm{r} 2}=\mathbf{3 7 8 ~ \mathbf { K ~ W } ^ { - 1 }} \\
\mathrm{h}_{\mathrm{c} 1}=79.5 \mathrm{~W} \mathrm{~m}^{-2} \mathrm{~K}^{-1} & \mathrm{~A}_{\mathrm{c} 1}=0.44 \mathrm{~m}^{2} & & \mathbf{R}_{\mathrm{c} 1}=\mathbf{0 . 0 2 9} \mathbf{K ~ W}^{-1} \\
\mathrm{~h}_{\mathrm{c} 2}=113 \mathrm{~W} \mathrm{~m}^{-2} \mathrm{~K}^{-1} & \mathrm{~A}_{\mathrm{c} 2}=0.44 \mathrm{~m}^{2} & & \mathbf{R}_{\mathrm{c} 2}=\mathbf{0 . 0 2 0} \mathbf{K ~ W}^{-1}
\end{array}
$$

Table 2. Hydrogen Absorber Network Node Temperatures for Various Total Absorber Heat Loads $Q_{T}$ with $Q_{C}+Q_{R}=30 W$

$\begin{array}{ccccc}\text { Node } & \mathrm{Q}_{\mathrm{T}}=40 \mathrm{~W} & \mathrm{Q}_{\mathrm{T}}=60 \mathrm{~W} & \mathrm{Q}_{\mathrm{T}}=80 \mathrm{~W} & \mathrm{Q}_{\mathrm{T}}=100 \mathrm{~W} \\ \mathrm{~T}_{\mathrm{R}}(\mathrm{K}) & 300 & 300 & 300 & 300 \\ \mathrm{~T}_{\text {win }}(\mathrm{K}) & 113 & 114 & 115 & 115 \\ \mathrm{~T}_{\mathrm{I}}(\mathrm{K}) & 75 & 76 & 77 & 77 \\ \mathrm{~T}_{\mathrm{f}}(\mathrm{K}) & 15.9 & 17.2 & 18.5 & 20.0 \\ \mathrm{~T}_{\mathrm{w}}(\mathrm{K}) & 15.6 & 16.4 & 17.2 & 18.0 \\ \mathrm{~T}_{\mathrm{He}}(\mathrm{K}) & 14.8 & 15.2 & 15.6 & 16.0 \\ \mathrm{~T}_{\mathrm{in}}(\mathrm{K}) & 14.0 & 14.0 & 14.0 & 14.0 \\ \mathrm{~T}_{\text {out }}(\mathrm{K})^{*} & 15.6 & 16.4 & 17.2 & 18.0 \\ \text { * This temperature is based on a helium gas mass flow of } 4.8 \mathrm{~g} / \mathrm{s} \text { entering from the refrigerator at } 14 \mathrm{~K} .\end{array}$


The same solution can be used for an absorber that contains sub-cooled liquid helium instead subcooled liquid hydrogen. The helium gas entering the absorber body at $14 \mathrm{~K}$ is replaced by two-phase helium entering the absorber body at $4.3 \mathrm{~K}$. The maximum allowable temperature for the helium is about $5.15 \mathrm{~K}$ (just below the critical temperature for helium) as compared to $20.3 \mathrm{~K}$ for hydrogen, so the maximum $\mathrm{T}_{\mathrm{f}}$ should be set at about $5.15 \mathrm{~K}$. Since the helium in the flow channel is boiling liquid helium at $4.3 \mathrm{~K}$, the heat transfer coefficient from the body wall to the helium $\mathrm{h}_{\mathrm{c} 2}$ is about $600 \mathrm{~W} \mathrm{~m}^{-2} \mathrm{~K}^{-1}$ for the amount heat per unit area going across the wall. The value of heat transfer coefficient between the sub-cooled liquid helium in the absorber and the absorber wall is about seventy percent of that for sub-cooled hydrogen. Thus on can use a value of $h_{c 1}=55 \mathrm{~W} \mathrm{~m}^{-2} \mathrm{~K}^{-1}$. The network resistances for the liquid hydrogen absorber with liquid helium in it can be postulated as shown in Tables 3 and 4.

Table 3. Data needed to balance the Heat Flow in the Liquid Helium Network shown in Figure 7

$\begin{array}{llll}\mathrm{l}_{11}=0.15 \mathrm{~m} & \mathrm{~A}_{11}=0.0012 \mathrm{~m}^{2} & \rho_{11}=4 \times 10^{-7} \Omega \mathrm{m} & \mathbf{R}_{11}=\mathbf{1 1 . 3 ~ K ~ \mathbf { W } ^ { - 1 }} \\ \mathrm{l}_{12}=0.10 \mathrm{~m} & \mathrm{~A}_{12}=0.0017 \mathrm{~m}^{2} & \rho_{12}=3.1 \times 10^{-8} \Omega \mathrm{m} & \mathbf{R}_{\mathbf{1} 2}=\mathbf{2 . 0 8} \mathbf{K ~ W}^{-1} \\ \mathrm{~T}_{\text {win }}=3.5 \times 10^{-4} \mathrm{~m} & & \rho_{\text {win }}=1.8 \times 10^{-8} \Omega \mathrm{m} & \mathbf{R}_{\text {win }}=\mathbf{3 . 7 5} \mathbf{K ~ W}^{-1} \\ \mathrm{e}=0.10 & \mathrm{~A}_{\text {win }}=0.22 \mathrm{~m}^{2} & & \mathbf{R}_{\mathrm{r} 1}=\mathbf{2 4 . 5} \mathbf{K ~ W}^{-1} \\ \mathrm{e}=0.10 & \mathrm{~A}_{\text {win }}=0.22 \mathrm{~m}^{2} & & \mathbf{R}_{\mathrm{r} 2}=\mathbf{4 2 3} \mathbf{K ~ W}^{-1} \\ \mathrm{~h}_{\mathrm{c} 1}=50 \mathrm{~W} \mathrm{~m}^{-2} \mathrm{~K}^{-1} & \mathrm{~A}_{\mathrm{c} 1}=0.44 \mathrm{~m}^{2} & & \mathbf{R}_{\mathrm{c} 1}=\mathbf{0 . 0 4 1} \mathbf{K ~ W}^{-1} \\ \mathrm{~h}_{\mathrm{c} 2}=568 \mathrm{~W} \mathrm{~m}^{-2} \mathrm{~K}^{-1} & \mathrm{~A}_{\mathrm{c} 2}=0.44 \mathrm{~m}^{2} & & \mathbf{R}_{\mathbf{c} 2}=\mathbf{0 . 0 0 4} \mathbf{K ~ W}^{-1}\end{array}$

Table 4. Helium Absorber Network Node Temperatures for Various Total Absorber Heat Loads $\mathrm{Q}_{\mathrm{T}}$ with $\mathrm{Q}_{\mathrm{C}}+\mathrm{Q}_{\mathrm{R}}=32 \mathrm{~W}$

$\begin{array}{ccccc}\text { Node } & \mathrm{Q}_{\mathrm{T}}=32 \mathrm{~W} & \mathrm{Q}_{\mathrm{T}}=37 \mathrm{~W} & \mathrm{Q}_{\mathrm{T}}=42 \mathrm{~W} & \mathrm{Q}_{\mathrm{T}}=47 \mathrm{~W} \\ \mathrm{~T}_{\mathrm{R}}(\mathrm{K}) & 300 & 300 & 300 & 300 \\ \mathrm{~T}_{\text {win }}(\mathrm{K}) & 106 & 106 & 106 & 106 \\ \mathrm{~T}_{\mathrm{I}}(\mathrm{K}) & 67 & 67 & 67 & 67 \\ \mathrm{~T}_{\mathrm{f}}(\mathrm{K}) & 4.43 & 4.66 & 4.89 & 5.12 \\ \mathrm{~T}_{\mathrm{w}}(\mathrm{K}) & 4.43 & 4.45 & 4.47 & 4.49 \\ \mathrm{~T}_{\mathrm{He}}(\mathrm{K}) & 4.30 & 4.30 & 4.30 & 4.30 \\ \mathrm{~T}_{\mathrm{in}}(\mathrm{K}) & 4.30 & 4.30 & 4.30 & 4.30 \\ \mathrm{~T}_{\text {out }}(\mathrm{K}) * & 4.30 & 4.30 & 4.30 & 4.30 \\ \text { * This temperature is based on a liquid helium mass flow of }>2.5 \mathrm{~g} / \mathrm{s} \text { entering from the refrigerator at } 4.3 \mathrm{~K} .\end{array}$

Table 4 shows that the maximum heat load that can be taken into the absorber fluid, when that fluid is liquid helium, is only about $15 \mathrm{~W}$. The total heat into the absorber fluid under that condition is about $47 \mathrm{~W}$. Most of the $47 \mathrm{~W}$ is heat leak from room temperature into the absorber through conduction and thermal radiation to the windows. While the MICE absorber can be filled with sub-cooled liquid helium in place of sub-cooled liquid hydrogen, the heat flow into the liquid helium is limited. The limits on heat transfer in the liquid helium absorber are due to a reduced heat transfer coefficient on the absorber fluid side and the smaller available temperature difference between the helium cooling fluid and the maximum allowable absorber fluid temperature (up to $6 \mathrm{~K}$ for $\mathrm{LH}_{2}$ and $0.8 \mathrm{~K}$ for helium). 


\section{The Absorber Body as a Counter Flow Heat Exchanger}

The absorber body with its cooling channel is nothing but a heat exchanger [3]. The fluid in the cooling channel flows across the cooling surface as a result of forced flow. The fluid on the absorber side of the heat exchanger is driven by natural convection. Since, the walls of the absorber are colder that the fluid in the absorber, the direction of fluid flow along the absorber wall will be in the downward direction. The flow of fluid in the cooling channel may be in either direction. If the flow in the cooling channel is also in the downward direction, the heat exchanger is a parallel-flow heat exchanger. If the flow direction of the fluid in the cooling channel is in the upward direction the heat exchanger is a counter-flow heat exchanger. If the cooling fluid enters the absorber body at the bottom (or top) and goes around the absorber and leaves the absorber at a point near where the fluid enters (the Japanese experiment with helium and liquid neon), the heat exchanger is a mixed parallel-flow and counter-flow heat exchanger. The three types of heat exchangers as applied to the liquid hydrogen absorber with helium cooling are illustrated in Figure 8. In Figure 8, the heat exchangers are in black; the helium in the body is represented by blue; and red arrows represent the sub-cooled liquid in the absorber.



Parallel Flow

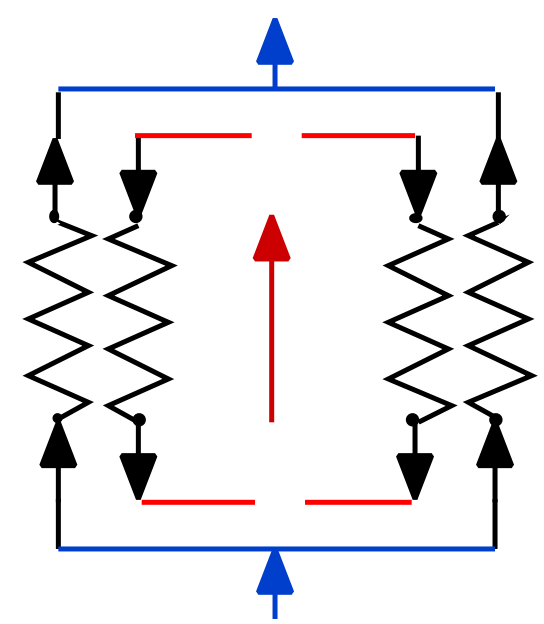

Counter Flow

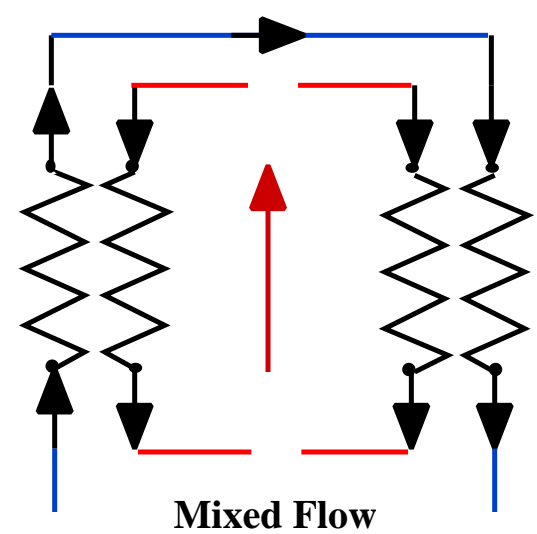

Figure 8. The Absorber Fluid and Shell represented as a Parallel-flow Heat Exchanger, a Counter-flow Heat Exchanger And a Mixed Flow Heat Exchanger. The cold helium is in blue, and the hydrogen is in red. 


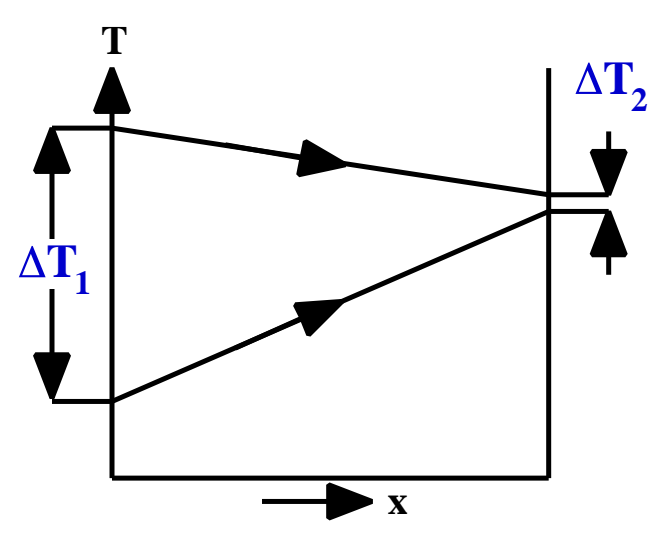

Parallel Flow

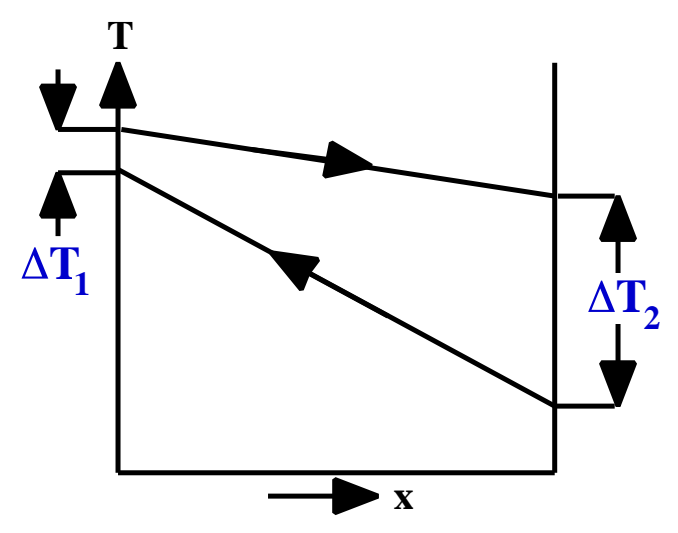

Counter Flow

Figure 9. The Temperature Profiles for a Typical Parallel-flow and Counter-flow Heat Exchanger No $\tau$ : $\Delta \mathrm{T}_{1}$ is the temperature difference across the heat exchange at one end; $\Delta \mathrm{T}_{2}$ is the temperature difference across the heat exchanger at the other end. These temperature differences are needed to find the log mean $\Delta \mathrm{T}$ for the heat exchanger

A typical temperature profile for the streams in a parallel-flow and a counter-flow heat exchanger is shown in Figure 9. The directions of the arrow on the steam temperature profiles indicate the direction of flow in the heat exchanger. Figure 9 illustrates that for a parallel-flow heat exchanger, the lowest temperature in the warm stream must always be higher that the highest temperature of the cold stream. For this not to be true is a violation of the second law of thermodynamics. This condition does not hold for a counter-flow heat exchanger where the highest temperature for the cold stream can be higher than the lowest temperature in the warm stream. As long at the temperature difference between the warm stream and the cold stream is greater than zero all the way along the heat exchanger, the second law of thermodynamics is not violated. When the total temperature drop between the warmstream and the cold-stream is limited, one always wants to use a counter-flow heat exchanger.

The pinch condition in the temperature between the two streams that is inherent in the parallelflow heat exchangers limits the log-mean (the effective) temperature-drop across the heat exchanger. For a given heat exchanger area and heat exchanger $\mathrm{U}$ factor (the average heat transfer coefficient across the heat exchanger), the counter-flow heat exchanger will nearly always transfer more heat than a parallel-flow heat exchanger. The instance where a parallel-flow heat exchanger is as effective as a counter-flow heat exchanger is when the warm stream is being condensed from a gas to a liquid or when the cold stream is being boiled from a liquid to a gas. In both cases, there is almost no change in the temperature along the stream where the phase change is occurring. The log mean temperature difference for the two types of heat exchangers is nearly the same. A subtle difference between the parallel-flow and counter-flow heat exchanger is the effect of buoyancy on the flow of the cold stream.

The mixed-flow heat exchanger has all of the disadvantages of the parallel flow heat exchanger plus the heat exchange is unbalanced. Since the warm end of the cold stream is in close proximity with the cold end of the cold stream in the MICE absorber, part of the cold stream heat exchanger area is used to transfer heat from the warm end of the cold stream to the cold end of the cold stream. This limits the heat exchanger performance of the mixed flow heat exchanger even more. 
It is clear that cooling of the absorber should use a pair of counter-flow heat exchangers with the cooled hydrogen going down the absorber walls and the helium gas going up the absorber wall on the other side. The two sides of the absorber will see balanced cooling, provided the heat exchanger is properly designed. It is reasonable to expect the heat exchanger $U$ factor to be the same on both left and right sides of the absorber heat exchanger. An identical orifice plate (with a pressure drop much higher than the flow stream pressure drop) on each helium flow circuit is needed to ensure that the flows in the two helium circuits will be the same and that heat transfer on both sides is reasonably balanced.

A second issue concerning the absorber heat exchanger is whether the flow on the absorber subcooled fluid side should be ducted. Ducting is always used on condensers and where boiling occurs. Ducting directs the flow in these instances and improves the heat transfer coefficient. Ducting should be useful in the absorber as well, provided there is enough space between the duct and the absorber wall. The absorber cross-section shown in Figure 4 shows a duct wall that directs the free convection flow down the inner wall of the absorber. Ducting prevents vortex formation between the rising stream and the falling stream. When a vortex is generated, entropy is expended [4], which is almost never a good thing. The ducts can also smooth out the stream lines, which can be useful in reducing the pressure drop along the free-convection stream. The presence of ducts allows one to look at the heat transfer in the heat exchanger differently. The heat exchanger can be treated as a standard heat exchanger on both sides. The mass flow on the free convection side is controlled by the buoyancy (the density change) of the heated absorber fluid and the pressure drop along the absorber fluid flow circuit. A potential downside of the ducts is the extra pressure drop in the absorber that they might cause. In my opinion, the advantages of using ducts outweigh the extra pressure drop they may cause. The heat exchanger analysis presented in the report assumes that the ducts are present in the absorber.

The heat exchanged between the absorber fluid and the cooling fluid in the absorber body Q can be calculated using the following expression:

$$
Q=U A_{H E} \Delta T_{L M}=\frac{T_{f}-T_{H e}}{R_{c 1}+R_{c 2}}
$$

where $\mathrm{U}$ is the heat transfer coefficient across heat exchanger and $\mathrm{A}_{\mathrm{HE}}$ is the average area of the heat exchanger. $\Delta \mathrm{T}_{\mathrm{LM}}$ is the log-mean temperature difference across the heat exchanger. The values for $\mathrm{UA}_{\mathrm{HE}}$ and $\Delta \mathrm{T}_{\mathrm{LM}}$ can be defined in terms of the network coefficients shown in Figure 7.

$$
U A_{H E}=\frac{1}{R_{c 1}+R_{c 2}}
$$

and

$$
\Delta L_{L M}=T_{f}-T_{H e} \quad-11 \mathrm{~b}-
$$

The relationship between the log-mean temperature difference and $\mathrm{T}_{\mathrm{f}}-\mathrm{T}_{\mathrm{He}}$ is not a surprise. The fact the $\mathrm{UA}_{\mathrm{HE}}$ is related to the resistance in the network in Figure 7 is not a surprise either. 
The heat exchanged across the heat exchanger $\mathrm{Q}$ is also the heat that is taken from the warm fluid as it is cooled from $\mathrm{T}_{\mathrm{h} 2}$ to $\mathrm{T}_{\mathrm{h} 1}$. This same heat warms the cold fluid from $\mathrm{T}_{\mathrm{c} 1}$ to $\mathrm{T}_{\mathrm{c} 2}$. Another expression for $\mathrm{Q}$, the heat transferred is:

$$
Q=M_{H e} \Delta H_{H e}=M_{H e} C_{H e}\left[T_{c 2}-T_{c 1}\right]
$$

and

$$
Q=M_{f} \Delta H_{f}=M_{f} C_{f}\left[T_{h 2}-T_{h 1}\right]
$$

where $\mathrm{M}_{\mathrm{He}}$ is the mass flow of the helium stream (the cold stream) and $\mathrm{M}_{\mathrm{f}}$ is the mass flow of the absorber fluid stream (the warm stream). $T_{c 2}$ is the high temperature in the cold stream; $T_{c 1}$ is low temperature in the cold stream; $\mathrm{T}_{\mathrm{h} 2}$ is the high temperature for the warm stream; and $\mathrm{T}_{\mathrm{h} 2}$ is the low temperature for the warm stream. $\Delta \mathrm{H}_{\mathrm{He}}$ is the change in enthalpy of the cold stream from $\mathrm{T}_{\mathrm{c} 1}$ to $\mathrm{T}_{\mathrm{c} 2}$, and $\Delta \mathrm{H}_{\mathrm{f}}$ is the change in enthalpy of the fluid in the absorber (the warm stream) from $\mathrm{T}_{\mathrm{f} 1}$ to $\mathrm{T}_{\mathrm{f} 2}$. $\mathrm{C}_{\mathrm{He}}$ is the specific heat at constant pressure for the helium in the cold stream. For helium gas at 2 bar from $14 \mathrm{~K}$ to $18 \mathrm{~K}, \mathrm{C}_{\mathrm{He}}=5220 \mathrm{~J} \mathrm{~kg}^{-1} \mathrm{~K}^{-1} . \mathrm{C}_{\mathrm{f}}$ is the average specific heat of the fluid in the absorber (the warm stream). For liquid hydrogen at 1 bar the average value of $\mathrm{C}_{\mathrm{f}}$ from $16 \mathrm{~K}$ to $20 \mathrm{~K}=\sim 9800 \mathrm{~J} \mathrm{~kg}^{-1} \mathrm{~K}^{-1}$. When two-phase helium at $4.3 \mathrm{~K}$ cools the 2 bar helium in the absorber, $\Delta \mathrm{H}_{\mathrm{He}}=19500 \mathrm{~J} \mathrm{~kg}^{-1}$ and the average value of $\mathrm{C}_{\mathrm{f}} \sim 6500 \mathrm{~J} \mathrm{~kg}^{-1} \mathrm{~K}^{-1}$. ( $\left(\mathrm{C}_{\mathrm{p}}\right.$ is higher than for liquid helium at $4.2 \mathrm{~K}$.)

It useful to note that in a counter-flow heat exchanger $\Delta \mathrm{T}_{1}=\mathrm{T}_{\mathrm{h} 2}-\mathrm{T}_{\mathrm{c} 2}$ and $\Delta \mathrm{T}_{2}=\mathrm{T}_{\mathrm{h} 1}-\mathrm{T}_{\mathrm{c} 1}$. One can define the log mean temperature difference $\Delta \mathrm{T}_{\mathrm{LM}}$ using $\Delta \mathrm{T}_{1}$ and $\Delta \mathrm{T}_{2}$ in the following expression:

$$
\Delta T_{L M}=\frac{\Delta T_{2}-\Delta T_{1}}{\ln \left[\frac{\Delta T_{2}}{\Delta T_{1}}\right]}
$$

The expression for $\Delta \mathrm{T}_{\mathrm{LM}}$ above applies for both parallel flow and counter flow heat exchangers.

Equation 13 can also be applied to the absorber once the heat exchange $U$ factor has been calculated. The heat exchanger $U$ factor times heat exchanger area $A_{\mathrm{HE}}$ can be estimated using the following expression;

$$
\frac{1}{U A_{H E}}=\frac{1}{h_{c 1} A_{c 1}}+\frac{4 \rho_{w} t_{w}}{L\left(T_{h 2}+T_{c 1}\right)\left(A_{c 1}+A_{c 2}\right)}+\frac{1}{h_{c 2} A_{c 2}}
$$

where $\rho_{\mathrm{w}}$ is the electrical resistivity of the heat exchanger wall material, $\mathrm{L}$ is the Lorenz number; and $\mathrm{t}_{\mathrm{w}}$ is the average thickness of the wall between the two heat transfer surfaces. For a finned heat exchanger the average wall thickness $\mathrm{t}_{\mathrm{w}}$ is the wall thickness between the fluid plus half the length of both fins.

Equation 14 can be simplified if the heat transfer area is approximately the same for both sides of the heat exchanger. In this case $\mathrm{A}_{\mathrm{HE}}=\mathrm{A}_{\mathrm{c} 1}=\mathrm{A}_{\mathrm{c} 2}$. The $\mathrm{U}$ factor for the heat exchanger can be calculated using the following expression 


$$
\frac{1}{U}=\frac{1}{h_{c 1}}+\frac{2 \rho_{w} t_{w}}{L\left(T_{h 2}+T_{c 1}\right)}+\frac{1}{h_{c 2}},
$$

and the heat exchanger area is defined as $\mathrm{A}_{\mathrm{HE}}$.

There are a couple of ways of extending the heat transfer surface in an absorber. The first is putting the heat exchanger in the absorber so that both sides of the heat exchange tube are exposed to the absorber fluid. This case is illustrated in Figure 10. This case results in a somewhat larger absorber body and the heat exchanger must be fabricated separately. A second approach is to machine fins on both sides of the absorber body wall so that both sides have and extended surface. This approach is illustrated in Figures 11 and 12. If this approach is done correctly, the size of the absorber body may be reduced. In both cases the absorber window diameter is assumed to be $300 \mathrm{~mm}$.

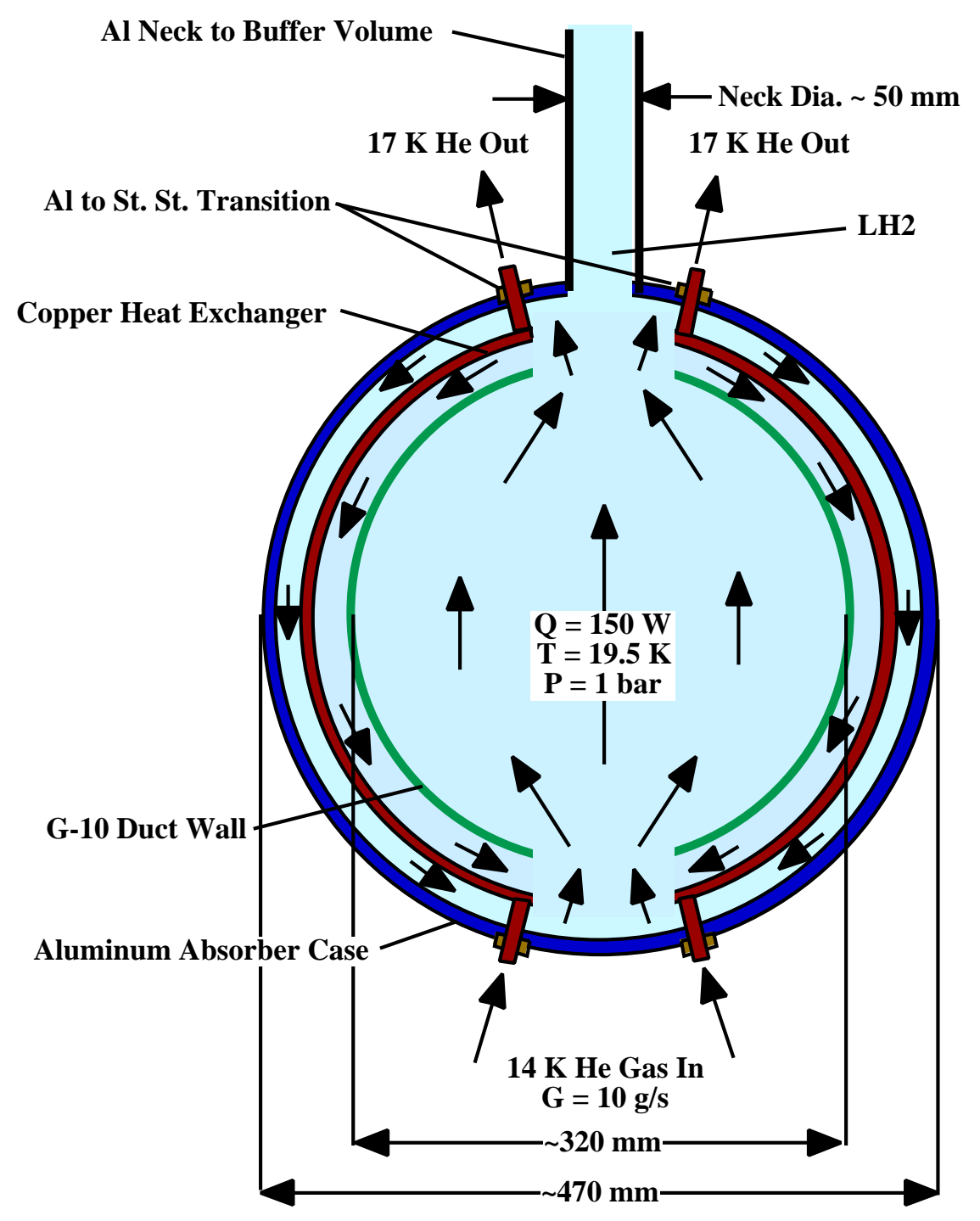

Figure 10. An Illustration of an Absorber with Cooling Tubes inside the Body so that All Sides of the Tubes are Cooled 


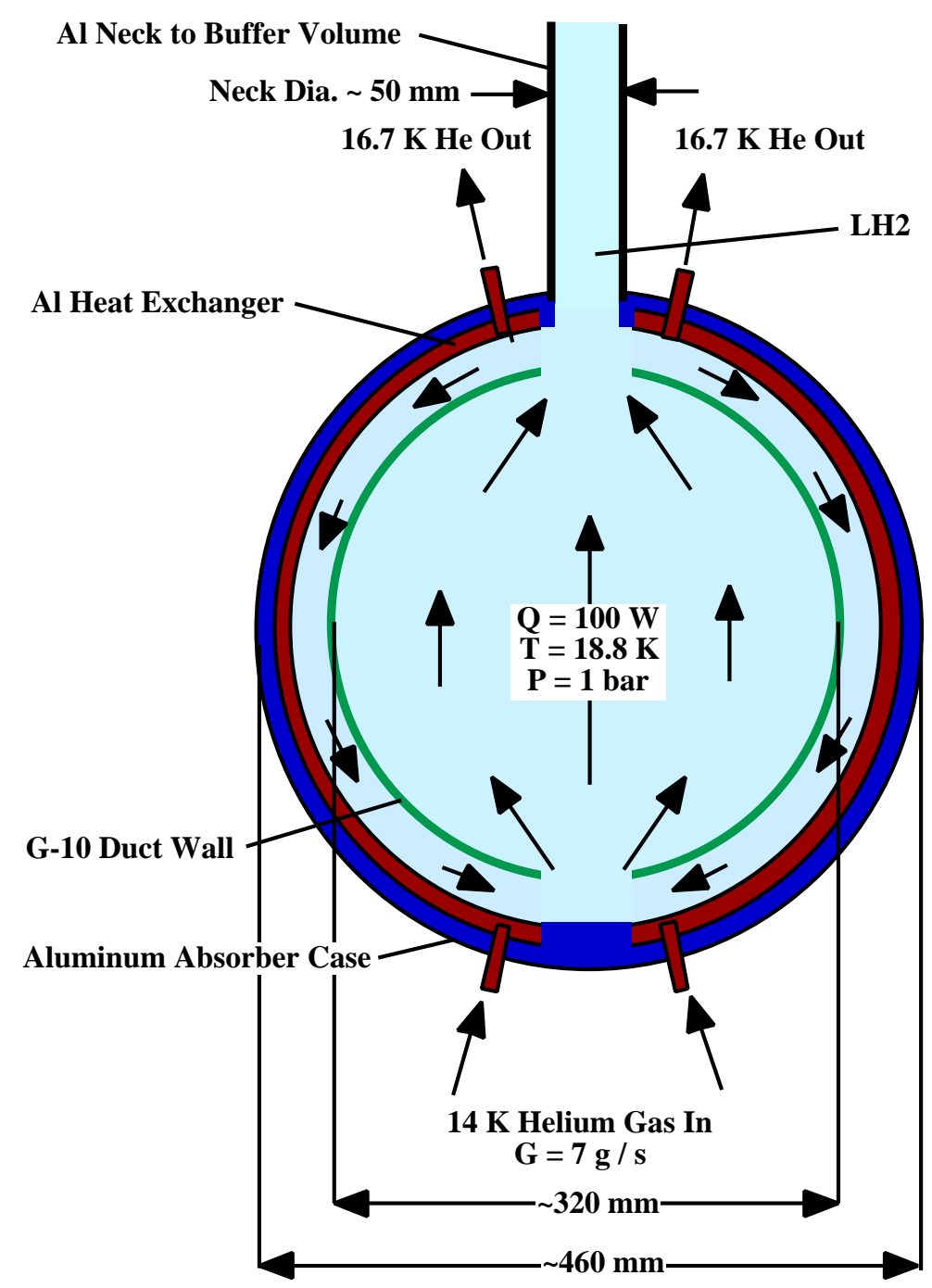

Figure 11. An Illustration of Cooling Tubes built into the Absorber Body

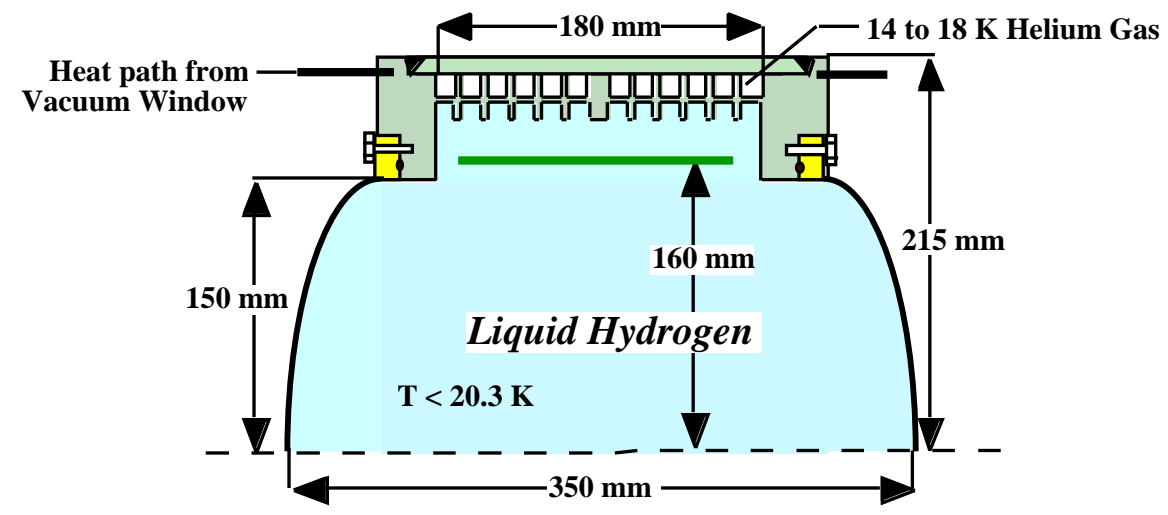

Figure 12. An Illustration of the Finned Extended Heat Transfer Surface on Both Sides of the Heat Exchanger 


\section{Calculation of the Heat Exchanger U Factor and Pressure Drops}

For this study, it is assumed that forced flow in tubes applies on both sides of the heat exchanger. The heat exchanger tubes are not round. In fact, heat exchanger tubes are far from being round. Two diameters will be used in the flow and heat transfer equations. The first is the effective diameter $\mathrm{D}_{\mathrm{E}}$; the second is the hydraulic diameter $\mathrm{D}_{\mathrm{H}}$. The first is used to calculate the pressure drop and fluid velocity in the pipe. The second diameter is the key diameter for calculating Reynolds number and Nusselts number. For round tubes $D_{H}=D_{E}$, which is the inside diameter of the tube. Equation for $D_{E}$ and $D_{H}$ are given as follows;

$$
D_{E}=\left[\frac{4 A_{c}}{\pi}\right]^{0.5}
$$

and

$$
D_{H}=\frac{4 A_{c}}{P}
$$

where $\mathrm{A}_{\mathrm{C}}$ is the cross-section area of the heat exchanger flow channel and $\mathrm{P}$ is the flow channel wetted perimeter. Putting fins into a rectangular flow channel will increase the channel's wetted perimeter. As a result, a channel with a given flow cross-section area will have a smaller hydraulic diameter when it has fins protruding into the channel.

Using the cross-section area $A_{C}$, one can calculate the fluid flow velocity in the tube $\mathrm{V}$ provided one knows the fluid mass flow $\mathrm{M}$ and the fluid density $\rho$. The fluid velocity is the channel is;

$$
V=\frac{M}{\rho A_{c}} .
$$

When Equation 16a is applied to Equation 17a given above, the fluid velocity $\mathrm{V}$ in the flow channel with an effective diameter $\mathrm{D}_{\mathrm{E}}$ takes the following form;

$$
V=\frac{4 M}{\pi \rho D_{E}^{2}} .
$$

A key dimensionless number used to calculate the heat transfer coefficient on the surface of a flow channel is the Reynolds number Re. The basic definition of Reynolds number is [3]:

$$
\operatorname{Re}=\frac{V \rho D_{H}}{\mu}
$$

$-18 \mathrm{a}-$

where $\mu$ is the viscosity of the fluid flowing through the flow channel. 
The Reynolds number equation given by Equation 18a can be manipulated using Equations 16a, $16 \mathrm{~b}$, and $17 \mathrm{a}$ to yield the following form;

$$
\mathrm{Re}=\frac{4 M}{P \mu} .
$$

For round tubes where $\mathrm{P}=\pi \mathrm{D}$, Reynolds number takes the following form;

$$
\operatorname{Re}=\frac{4 M}{\pi D \mu}
$$

$-18 c-$

For round annular tubes with a thin annulus (the inner diameter of the annulus is nearly equal to the outer diameter of the annulus) such that $\mathrm{P}=2 \pi \mathrm{D}$, Reynolds number takes the following form;

$$
\operatorname{Re}=\frac{2 M}{\pi D \mu}
$$

despite the fact that the fluid velocity in thin annulus can be very high.

The Nusselts number relates the heat transfer coefficient on the channel surface $h_{c}$ to the thermal conductivity of the fluid $\mathrm{k}_{\mathrm{f}}$ and the channel hydraulic diameter $\mathrm{D}_{\mathrm{H}}$. The general form for the Nusselts number in a flow channel is as follows [3];

$$
N u=\frac{h_{c} D_{H}}{k_{f}} .
$$

The final dimensionless number used to calculate the heat transfer coefficient in a channel is the Prandtl number Pr. The Prandtl number is the ratio of the fluid specific heat at constant pressure $\mathrm{C}_{\mathrm{f}}$ times the fluid viscosity $\mu$ to the fluid thermal conductivity of the fluid $\mathrm{k}_{\mathrm{f}}$. In simple terms, the Prandtl number relates the thickness of the thermal boundary layer to the thickness of the viscosity boundary layer. An expression for the Prandtl number is given as follows [3];

$$
\operatorname{Pr}=\frac{C_{f} \mu}{k_{f}}
$$

The form the Nusselts number takes for flow in the channel depends on whether the flow in the channel is laminar (no boundary layer is formed in the channel) or whether the flow is turbulent (a boundary layer is on the wall of the channel). For flow in a tube or a flow channel, the transition from laminar and turbulent flow occurs at a Reynolds number of about 1200. The dividing line between turbulent and laminar flow is not particularly sharp. If the channel surface is very smooth and there are not quick channel changes the transition may occur at Reynolds numbers as high as 10000. A little roughness on the channel surface will ensure that the transition $\operatorname{Re}<1500$. 
For the cases studied for the absorber-cooling channel, the flow is turbulent. For turbulent flow in either channel, the flow Nusselts number can be calculated using the following equation [3],[5].

$$
N u=0.023 \operatorname{Re}^{0.8} \operatorname{Pr}^{0.33} .
$$

The forced convection heat transfer coefficient on the channel surface $h_{c}$ can be derived from Equation 21 and Equation 19. The heat transfer coefficient equation takes the following form;

$$
h_{c}=0.023 \operatorname{Re}^{0.8} \operatorname{Pr}^{0.33} \frac{k_{f}}{D_{H}} .
$$

Equation 22a can be separated out into a form that lumps mass flow $\mathrm{M}$, channel properties $\mathrm{P}$ and $\mathrm{A}_{\mathrm{C}}$, and fluid properties $k_{f}, C_{f}$, and $\mu$ into separate groups. Equation 22a in a separated form is as follows;

$$
h_{c}=0.0174\left[M^{0.8}\right]\left[{\frac{P}{A_{c}}}^{0.2}\right]\left[\frac{C_{f}^{0.33} k_{f}^{0.67}}{\mu^{0.47}}\right] \text {. }
$$

For a round tube channel of Diameter D, Equation 22b takes the following form;

$$
\left.h_{c}=0.0279\left[M^{0.8}\right] \frac{1}{D^{1.8}}\right]\left[\frac{C_{f}^{0.33} k_{f}^{0.67}}{\mu^{0.47}}\right] .
$$

It is clear from Equations $22 \mathrm{~b}$ and $22 \mathrm{c}$, that one wants to maximize $\mathrm{P}$ and minimize $\mathrm{A}_{\mathrm{C}}$ in order to maximize the heat transfer coefficient in a channel for a given fluid mass flow $M$. This works for the helium gas side of the heat exchanger where there is up to $0.2 \mathrm{MPa}$ of available pressure to drive the fluid through the flow channel. On the liquid hydrogen side one must be very careful, because the available pressure drop is the pressure due to differing densities of the fluid in the central region of the absorber as compared to the fluid in the cooling channel next to the absorber wall.

The pressure drop $\Delta \mathrm{P}$ in a smooth flow channel with fluid flowing in turbulent flow can be estimated using the following general expression;

$$
\Delta P=\frac{8 M^{2}}{\pi^{2} \rho} \frac{1}{D_{E}^{4}}\left[F+f \frac{L_{c h}}{D_{H}}\right],
$$

where $M$ is the channel mass flow, $\rho$ is the fluid density; $D_{E}$ is the effective channel diameter; $F$ is a factor that is a function of the number of channel bends, the type of bends, and the pressure drop through offices and other such things; $\mathrm{L}_{\mathrm{ch}}$ is the channel length; $\mathrm{D}_{\mathrm{H}}$ is the channel hydraulic diameter and $f$ is the channel friction factor. The friction factor $f$ in turbulent flow for smooth pipes can be estimated using the following expression; 


$$
f=0.184 \mathrm{Re}^{-0.2}=0.139 \frac{P^{0.2} \mu^{0.2}}{M^{0.2}}
$$

Using Equations 23, 24, 16a and 16b, one can come up with an expression that describes the pressure drop in the channel that separates out the mass flow $\mathrm{M}$, the channel parameters, and the fluid parameters. This expression for the pressure drop takes the following form;

$$
\Delta P=F \frac{M^{2}}{2} \frac{1}{A_{c}^{2}} \frac{1}{\rho}+0.0218\left[M^{1.8}\right] \frac{P^{1.2} L_{c h}}{A_{c}^{3}} \frac{\mu^{0.2}}{\rho}
$$

For a round tube channel with a diameter D, Equation 25a takes the following form;

$$
\Delta P=\frac{8}{\pi^{2}} F M^{2} \frac{1}{D^{4}} \frac{1}{\rho}+0.0222\left[M^{1.8}\right] \frac{L_{c h}}{D^{4.8}} \frac{\mu^{0.2}}{\rho} .
$$

For short channels $\left(\mathrm{L}_{\mathrm{ch}} / \mathrm{D}_{\mathrm{H}}<20\right)$ that have a large bends at the ends and an opening up of the channel at the ends, $\mathrm{F}$ will be greater than 2, so the first term in Equation 25a will dominate over the second term (the pipe friction term). The pressure drop $\Delta \mathrm{P}_{\mathrm{f}}$ for the flow channel in the absorber body with a mass flow of $\mathrm{M}_{\mathrm{f}}$ will have the following approximate value;

$$
\Delta P_{f}=\frac{1.5}{\rho}\left[\frac{M_{f}}{A_{c}}\right]^{2}
$$

On the absorber side of the heat exchanger, the flow in the channel is determined by the difference in the average density of the fluid in the absorber and the average density of the fluid in the flow channel next to the absorber wall. The driving head $\Delta \mathrm{P}_{\mathrm{DR}}$ can be estimated using the following expression;

$$
\Delta P_{D R}=-\frac{D_{A} \beta}{2} \gamma \rho\left(T_{h 2}-T_{h 1}\right)
$$

where $D_{A}$ is the absorber body inside diameter; $\gamma$ is the acceleration of gravity $\left(\gamma=9.8 \mathrm{~m} \mathrm{~s}^{-2}\right)$; $T_{h 2}$ is the highest temperature in the absorber fluid; $T_{h 1}$ is the lowest temperature in the absorber fluid; $\rho$ is the average density of the absorber fluid; and $\beta$ is the average density change factor per degree $\mathrm{K}$ in the absorber fluid. (For sub-cooled liquid hydrogen at $18 \mathrm{~K}, \beta=-0.021 \mathrm{~K}^{-1}$, and for sub-cooled liquid helium at $4.6 \mathrm{~K}, \beta=-0.202 \mathrm{~K}^{-1}$.) (For sub-cooled hydrogen at $18 \mathrm{~K}$ and $1.2 \mathrm{bar}, \rho=75.3 \mathrm{~kg} \mathrm{~m}^{-3}$, and for sub-cooled liquid helium at $4.6 \mathrm{~K}$ and 2.1 bar, $\rho=121.9 \mathrm{~kg} \mathrm{~m}^{-3}$.)

When the pressure drop given by equation 26 is equal to the pressure head given by equation 27 , one determine the mass flow of absorber fluid that passes through the flow channel that is next to the absorber walls. An estimate of the mass flow $\mathrm{M}$ in the duct on the absorber side of the heat exchanger can be given by the following expression; 


$$
M_{f}=\rho A_{c}\left[\frac{D_{A} \beta \gamma\left(T_{h 2}-T_{h 1}\right)}{3}\right]^{0.5} .
$$

It is interesting to note that the desired mass flow $\mathrm{M}_{\mathrm{f}}$ is determined by the temperature difference along the stream (see Equation 12b). One can set the desired temperature difference along the flow stream $\left(\mathrm{T}_{\mathrm{h} 2}-\mathrm{T}_{\mathrm{h} 1}\right)$ for a given heat flow across the heat exchanger $\mathrm{Q}$. Once one determines the desired mass flow from the desired temperature difference, one can determine the cross-sectional area of the flow channel. Using Equation 12b and Equation 28, the following expression for the channel crosssectional area $\mathrm{A}_{\mathrm{c}}$ results;

$$
A_{c}=1.73 \frac{Q}{C_{f} \rho}\left[D_{A} \beta \gamma\right]^{0.5}\left[T_{h 2}-T_{h 1}\right]^{-1.5}
$$

When one looks at Figure 12, the sub-cooled hydrogen channel shown has $a=0.2 \mathrm{~m}, \mathrm{~b}=0.03 \mathrm{~m}$ with an $A_{c}=0.006 \mathrm{~m}^{2}$. This channel can carry a heat load $\mathrm{Q}=50 \mathrm{~W}$ with a temperature difference along the stream $\left(\mathrm{T}_{\mathrm{h} 2}-\mathrm{T}_{\mathrm{h} 1}\right)=0.17 \mathrm{~K}$. If the heat load carried by the channel is decreased to $12.5 \mathrm{~W}$ (a factor of 4 decrease) the temperature difference along the channel will decrease as by a factor of 2 . The channel mass flow will also decrease by a factor of 2 . For the channel in Figure 12, a heat load of $50 \mathrm{~W}$ can be transferred with a temperature drop $\left(\mathrm{T}_{\mathrm{h} 2}-\mathrm{T}_{\mathrm{h} 1}\right)=0.17 \mathrm{~K}$, the free convection mass flow through that channel will be $0.0307-\mathrm{kg} \mathrm{s}^{-1}$. If the heat load in the channel is $100 \mathrm{~W}$, the temperature drop $\left(\mathrm{T}_{\mathrm{h} 2}-\right.$ $\mathrm{T}_{\mathrm{h} 1}$ ) will increase to $0.24 \mathrm{~K}$ while the channel mass flow increases to $0.0434-\mathrm{kg} \mathrm{s}^{-1}$.

From Equation 28, one can see that the free convection mass flow $\mathrm{M}_{\mathrm{f}}$ in the channel will decrease proportionately with the channel cross-section area $A$. In doing so the temperature drop $\left(\mathrm{T}_{\mathrm{h} 2}-\mathrm{T}_{\mathrm{h} 1}\right)$ must increase in order for the heat to be removed. If the channel dimensions in Figure 12 were reduced so that $\mathrm{a}=0.2 \mathrm{~m}$ and $\mathrm{b}=0.015 \mathrm{~m}\left(\mathrm{~A}_{\mathrm{C}}=0.003 \mathrm{~m}^{2}\right)$ and the channel heat load $\mathrm{Q}=50 \mathrm{~W}$, the channel mass flow $\mathrm{M}_{\mathrm{f}}$ would decrease to $0.0217 \mathrm{~kg} \mathrm{~s}^{-1}$ while the temperature drop along the channel $\left(\mathrm{T}_{\mathrm{h} 2}-\mathrm{T}_{\mathrm{h} 1}\right)$ would increase to $0.24 \mathrm{~K}$. For a given heat load transferred by free convection, a change in cross-sectional area by a factor of two decreases the fluid mass flow by a factor of square root of two while increasing the fluid temperature drop to transfer the heat by a factor of square root of two.

\section{Heat Exchanger $U$ factor and End Point Temperatures for the Baseline Absorber}

The heat transfer coefficients for both streams can be calculated using either Equation 22a or Equation 22b. These calculations can be done for an absorber that contains either liquid hydrogen or liquid helium. In the liquid helium case, the absorber body tubes contain two-phase helium at $4.3 \mathrm{~K}$. Given the nature of boiling in these tubes, a heat transfer coefficient $\mathrm{h}_{\mathrm{cHe}}=625 \mathrm{~W} \mathrm{~m}^{-2} \mathrm{~K}^{-1}$ can be used. Based on measurements done at on boiling helium in tubes, this value is conservative. Table 5 presents the parameter used to calculate $h_{c}$ on both walls of the heat exchanger between the absorber glow channel and the cooling flow channel. In order to calculate the solid conduction term in Equation 15 (the middle term), the $U$ factor equation, some assumptions must be made. These assumptions are: for a hydrogen absorber $\mathrm{T}_{\mathrm{w}}=16 \mathrm{~K}$, for a helium absorber $\mathrm{T}_{\mathrm{w}}=4.7 \mathrm{~K} ; \rho_{\mathrm{w}}=1.8 \times 10^{-8} \Omega \mathrm{m}$, and $\mathrm{t}_{\mathrm{w}}=0.007 \mathrm{~m}$. 
Table 5. Parameters used to Calculate the Heat Transfer Coefficients for the Absorber Heat Exchanger

Parameter

$\begin{array}{cc}\mathrm{A}_{\mathrm{C}}\left(\mathrm{m}^{2}\right) & 0.0024 \\ \mathrm{P}(\mathrm{m}) & 0.96 \\ \text { Property T }(\mathrm{K}) & 16 \\ \mathrm{C}_{\mathrm{f}}\left(\mathrm{J} \mathrm{kg}^{-1} \mathrm{~K}^{-1}\right) & 5220 \\ \mathrm{k}_{\mathrm{f}}\left(\mathrm{W} \mathrm{m}^{-1} \mathrm{~K}^{-1}\right) & 0.023 \\ \mu_{\mathrm{f}}\left(\mathrm{kg} \mathrm{m}^{-1} \mathrm{~s}^{-1}\right) & 3.37 \times 10^{-6} \\ \rho_{\mathrm{f}}\left(\mathrm{kg} \mathrm{m}^{-3}\right) & 6.16\end{array}$

Free Convection Side

$\begin{array}{cc}\text { Hydrogen } & \text { Helium } \\ 0.006 & 0.006 \\ 0.86 & 0.86 \\ 18 & 4.6 \\ 9800 & 6500 \\ 0.113 & 0.019 \\ 16.1 \times 10^{-6} & 3.10 \times 10^{-6} \\ 75.3 & 121.9\end{array}$

For the absorber containing sub-cooled liquid hydrogen, the mass flow on the helium forced flow side $\mathrm{M}_{\mathrm{He}}$ is arbitrary. Calculations were done for various helium gas flows from 0.002 , to $0.02-\mathrm{kg} \mathrm{s}^{-1}$ for both channels. The values for $\mathrm{M}_{\mathrm{f}}$ used in the calculation depend on the heat being transferred $\mathrm{Q}$ by free convection. For the absorber containing hydrogen, $\mathrm{M}_{\mathrm{f}}=0.022 \mathrm{~kg} \mathrm{~s}^{-1}$ when $\mathrm{Q}=50 \mathrm{~W}$ for both channels; $\mathrm{M}_{\mathrm{f}}=0.031 \mathrm{~kg} \mathrm{~s}^{-1}$ when $\mathrm{Q}=100 \mathrm{~W}$ for both channels; $\mathrm{M}_{\mathrm{f}}=0.038 \mathrm{~kg} \mathrm{~s}^{-1}$ when $\mathrm{Q}=150 \mathrm{~W}$ for both channels; and $\mathrm{M}_{\mathrm{f}}=0.043 \mathrm{~kg} \mathrm{~s}^{-1}$ when $\mathrm{Q}=200 \mathrm{~W}$ for both channels.

When the absorber contains sub-cooled liquid helium at $0.2 \mathrm{MPa}$, the helium that cools the absorber within the case is two-phase helium at $4.3 \mathrm{~K}$. The flow rate of the helium depends on the total amount of heat being removed from the absorber. The minimum two-phase helium mass flow is the total heat load into the absorber form all sources divided by the heat of vaporization of the helium. The heat of vaporization for helium at $4.3 \mathrm{~K}$ is $19500 \mathrm{~J} \mathrm{~kg}^{-1}$. For absorber containing sub-cooled liquid helium, $\mathrm{M}_{\mathrm{f}}=0.0173 \mathrm{~kg} \mathrm{~s}^{-1}$ when $\mathrm{Q}=5 \mathrm{~W}$ for both channels; $\mathrm{M}_{\mathrm{f}}=0.0244 \mathrm{~kg} \mathrm{~s}^{-1}$ when $\mathrm{Q}=10 \mathrm{~W}$ for both channels; $M_{\mathrm{f}}=0.0300 \mathrm{~kg} \mathrm{~s}^{-1}$ when $\mathrm{Q}=15 \mathrm{~W}$ for both channels; $\mathrm{M}_{\mathrm{f}}=0.0346 \mathrm{~kg} \mathrm{~s}^{-1}$ when $\mathrm{Q}=20$ for both channels; and so on.

Table 6 presents the average heat transfer coefficient times average heat exchanger area UA and the log mean temperature difference $\Delta \mathrm{T}_{\mathrm{LM}}$ for the sub-cooled liquid hydrogen absorber at various helium gas mass flows and various heat loads into the hydrogen in the absorber. At low helium gas mass flows, the UA factor is controlled by $h_{c 2} A_{c 2}$ on the helium gas side of the heat exchanger. At high helium gas mass flows the UA factor is controlled by $h_{c 1} A_{c 1}$ on the hydrogen side of the heat exchanger. In all cases the temperature drop across the heat exchanger wall is small compared to the temperature drop across the fluid boundary layers. Figure 13 shows a plot of the highest hydrogen temperature as a function of the cooling gas mass flow and heat load. The UA factors in Table 6 are generated using the values of $\mathrm{C}$, $\mathrm{k}, \mu$, and $\rho$ shown in Table 5. When the average temperature in the heat exchanger is higher than shown in Table 5, the UA factor will be a little higher than shown in Table 6, and vice versa.

Table 7 presents the average heat transfer coefficient times average heat exchanger area UA and the $\log$ mean temperature difference $\Delta \mathrm{T}_{\mathrm{LM}}$ for the sub-cooled liquid helium absorber at a pressure of 0.2 $\mathrm{MPa}$ for various heat loads into the helium in the absorber. In all cases, the UA factor is controlled by $\mathrm{h}_{\mathrm{cl}} \mathrm{A}_{\mathrm{cl}}$ on the sub-cooled liquid helium side of the heat exchanger. The temperature drops across the boiling liquid helium and the heat exchanger wall are small. Figure 14 shows a plot of the highest sub- 
cooled helium temperature in the absorber as a function of the heat load. The two-phase helium flow is high enough in all cases so that boiling will occur all along the cooling channel. The UA factors in Table 7 are generated using the values of $\mathrm{C}, \mathrm{k}, \mu$, and $\rho$ shown in Table 5. When the average temperature in the heat exchanger is higher than shown in Table 5, the UA factor will be a little higher than shown in Table 7, and vice versa.

Table 6. The Heat Exchanger UA Factor and $\Delta \mathrm{T}_{\mathrm{LM}}$ for the Liquid Hydrogen Absorber as a Function of Helium Gas Mass Flow in the Jacket and the Total Heat Load into the Absorber

\begin{tabular}{|c|c|c|c|c|c|}
\hline Mass Flow $\left(\mathrm{kg} \mathrm{s}^{-1}\right)$ & & $\mathrm{Q}=50 \mathrm{~W}$ & $\mathrm{Q}=100 \mathrm{~W}$ & $\mathrm{Q}=150 \mathrm{~W}$ & $\mathrm{Q}=200 \mathrm{~W}$ \\
\hline \multirow[t]{2}{*}{0.002} & $\mathrm{UA}\left(\mathrm{W} \mathrm{K}^{-1}\right)$ & 11.53 & 12.26 & 12.63 & 12.86 \\
\hline & $\Delta \mathrm{T}_{\mathrm{LM}}(\mathrm{K})$ & 4.33 & 8.16 & 11.88 & 15.55 \\
\hline \multirow[t]{2}{*}{0.0035} & $\mathrm{UA}\left(\mathrm{W} \mathrm{K}^{-1}\right)$ & 15.82 & 17.21 & 17.96 & 18.42 \\
\hline & $\Delta \mathrm{T}_{\mathrm{LM}}(\mathrm{K})$ & 3.16 & 5.81 & 8.35 & 10.86 \\
\hline \multirow[t]{2}{*}{0.005} & $\mathrm{UA}\left(\mathrm{W} \mathrm{K}^{-1}\right)$ & 18.91 & 20.92 & 22.03 & 22.73 \\
\hline & $\Delta \mathrm{T}_{\mathrm{LM}}(\mathrm{K})$ & 2.64 & 4.78 & 6.81 & 8.80 \\
\hline \multirow[t]{2}{*}{0.0075} & $\mathrm{UA}\left(\mathrm{W} \mathrm{K}^{-1}\right)$ & 22.58 & 25.52 & 27.18 & 28.26 \\
\hline & $\Delta \mathrm{T}_{\mathrm{LM}}(\mathrm{K})$ & 2.21 & 3.92 & 5.52 & 7.08 \\
\hline \multirow[t]{2}{*}{0.010} & $\mathrm{UA}\left(\mathrm{W} \mathrm{K}^{-1}\right)$ & 25.26 & 29.94 & 31.16 & 32.58 \\
\hline & $\Delta \mathrm{T}_{\mathrm{LM}}(\mathrm{K})$ & 1.98 & 3.34 & 4.81 & 6.14 \\
\hline \multirow[t]{2}{*}{0.0125} & $\mathrm{UA}\left(\mathrm{W} \mathrm{K}^{-1}\right)$ & 27.26 & 31.66 & 34.26 & 35.98 \\
\hline & $\Delta \mathrm{T}_{\mathrm{LM}}(\mathrm{K})$ & 1.83 & 3.16 & 4.38 & 5.55 \\
\hline \multirow[t]{2}{*}{0.015} & $\mathrm{UA}\left(\mathrm{W} \mathrm{K}^{-1}\right)$ & 28.91 & 33.91 & 36.91 & 38.93 \\
\hline & $\Delta \mathrm{T}_{\mathrm{LM}}(\mathrm{K})$ & 1.73 & 2.95 & 4.06 & 5.14 \\
\hline \multirow[t]{2}{*}{0.0175} & $\mathrm{UA}\left(\mathrm{W} \mathrm{K}^{-1}\right)$ & 30.13 & 35.60 & 38.93 & 41.17 \\
\hline & $\Delta \mathrm{T}_{\mathrm{LM}}(\mathrm{K})$ & 1.66 & 2.81 & 3.85 & 4.85 \\
\hline \multirow[t]{2}{*}{0.020} & $\mathrm{UA}\left(\mathrm{W} \mathrm{K}^{-1}\right)$ & 31.26 & 37.19 & 40.83 & 43.31 \\
\hline & $\Delta \mathrm{T}_{\mathrm{LM}}(\mathrm{K})$ & 1.60 & 2.69 & 3.67 & 4.62 \\
\hline
\end{tabular}

Table 7. The Heat Exchanger UA Factor and $\Delta \mathrm{T}_{\mathrm{LM}}$ for the Helium Absorber as a Function of the Total Heat Load into the Absorber

$\begin{array}{ccc}\text { Heat Load }(\mathrm{W}) & \mathrm{UA} \text { Factor }\left(\mathrm{W} \mathrm{K}^{-1}\right) & \Delta \mathrm{T}_{\mathrm{LM}}(\mathrm{K}) \\ 5 & 21.74 & 0.23 \\ 10 & 27.86 & 0.36 \\ 15 & 31.64 & 0.47 \\ 20 & 35.03 & 0.57 \\ 25 & 37.61 & 0.67 \\ 30 & 39.82 & 0.75\end{array}$




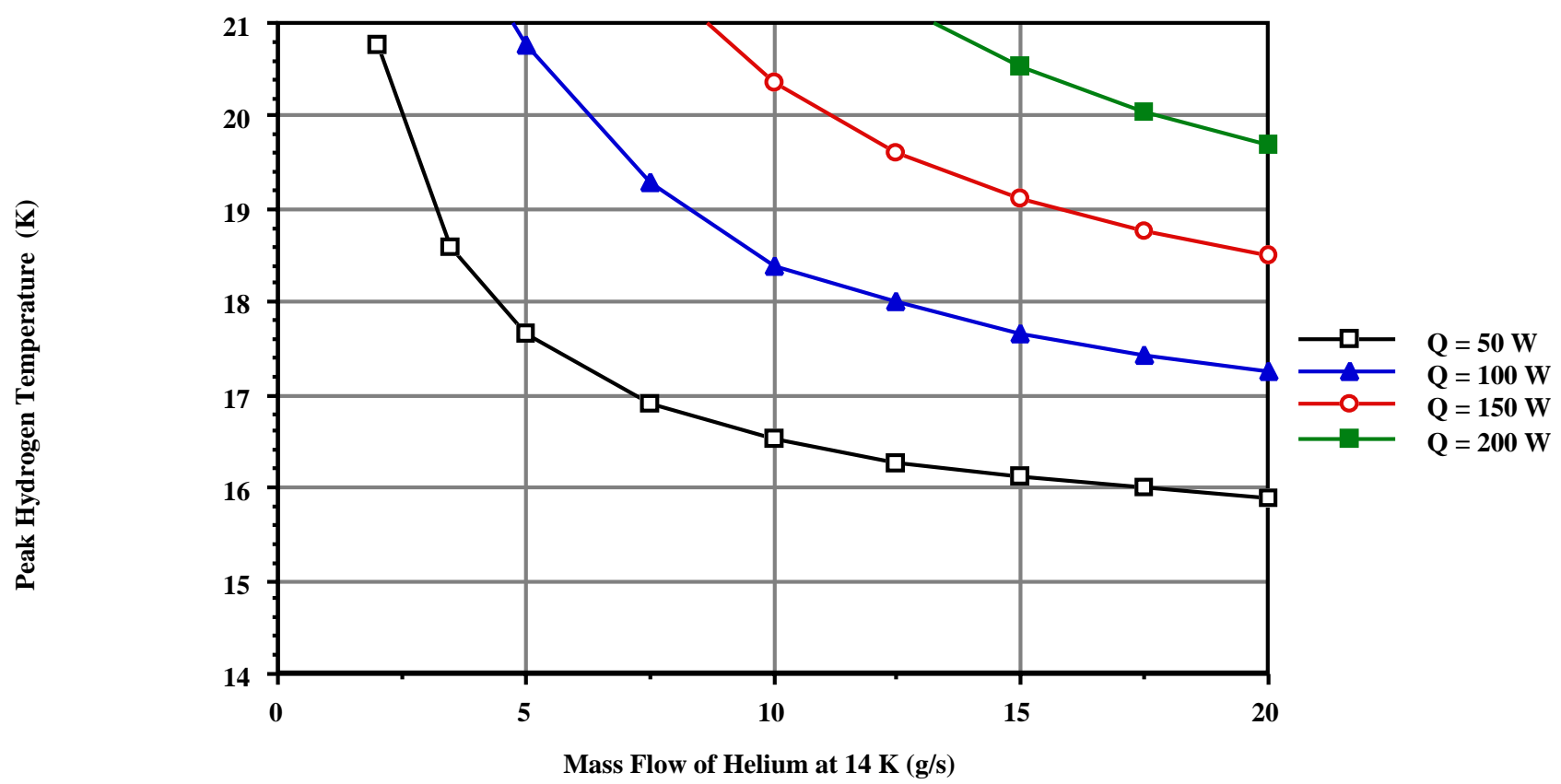

Figure 13. The Peak Temperature in the Sub-cooled Hydrogen in a Hydrogen Absorber as a Function of the Heat load into the Absorber and the Mass Flow of Helium Gas Cooling Entering the Absorber at $14 \mathrm{~K}$

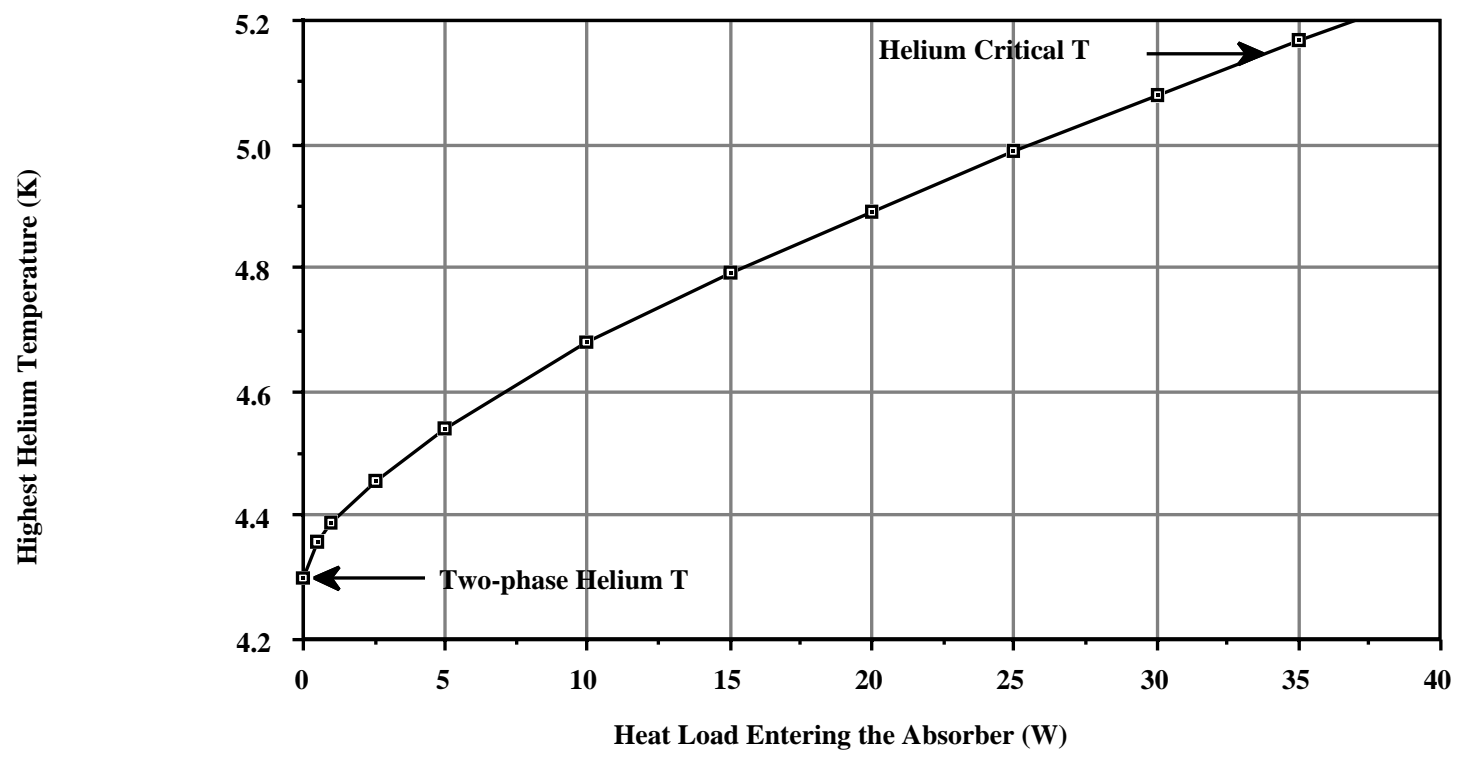

Figure 14. The Peak Temperature in the Sub-cooled Helium at 2 bar in a Helium Absorber as a Function of the Heat load into the Absorber. The helium absorber is cooled by at least $2.5 \mathrm{~g} \mathrm{~s}^{-1}$ of two-phase helium at $4.3 \mathrm{~K}$.

From Figure 13, one can see that one can remove up to $100 \mathrm{~W}$ of heat into a sub-cooled liquid hydrogen absorber with a mass flow of helium gas of $5-\mathrm{g} \mathrm{s}^{-1}$ entering the absorber case at $14 \mathrm{~K}$. It is interesting to compare the calculated UA factors in Table 6, with the UA factor assumed in Table 1. The average UA factor $\left(\mathrm{UA}=1 /\left(\mathrm{R}_{\mathrm{c} 1}+\mathrm{R}_{\mathrm{c} 2}\right)\right.$ from Table 1 is $20.4 \mathrm{~W} \mathrm{~K}^{-1}$. In order to remove $200 \mathrm{~W}$ of heat the helium gas mass flow must be increased to something of the order of $16-\mathrm{g} \mathrm{s}^{-1}$ for the peak 
hydrogen temperature to be less than $20.3 \mathrm{~K}$ (the normal. boiling temperature for hydrogen). From Figure 13, one see that the helium-gas flow strongly influences the peak hydrogen temperature in a liquid hydrogen absorber. The flow control for the helium gas cooling circuit in the hydrogen absorber can be based on the hydrogen pressure in the absorber. It is interesting to note that when $200 \mathrm{~W}$ is put into the hydrogen, the peak temperature change in the hydrogen is about $0.24 \mathrm{~K}$. The density change in the hydrogen stream is about 0.5 percent, which is well within the acceptable range for a liquid hydrogen absorber.

From Figure 14, one can see that up $30 \mathrm{~W}$ can be deposited in the sub-cooled helium at $0.2 \mathrm{MPa}$ in the absorber without raising its temperature or pressure above the critical point (5.17 $\mathrm{K}$ at $0.219 \mathrm{MPa})$. It is interesting to compare the calculated UA factors in Table 7, with the UA factor assumed in Table 2. The average UA factor $\left(\mathrm{UA}=1 /\left(\mathrm{R}_{\mathrm{c} 1}+\mathrm{R}_{\mathrm{c} 2}\right)\right.$ from Table 2 is $22.2 \mathrm{~W} \mathrm{~K}^{-1}$. The flow control for the twophase helium cooling circuit in the helium absorber can be based on the helium pressure in the absorber body. It is interesting to note that when $30 \mathrm{~W}$ is put into the liquid helium, the peak temperature change in the helium is about $0.055 \mathrm{~K}$. The density change in the helium is about 1.1 percent, which is well within the acceptable range for a liquid helium absorber. Since the temperature drop across the wall and from the wall to the boiling two-phase helium is less than 20 percent of the total temperature drop across the heat exchanger, on can put $30 \mathrm{~W}$ into the absorber body (by conduction and radiation) and still put over $20 \mathrm{~W}$ into the sub-cooled liquid helium in the absorber. This suggests that the MICE absorber can be operated with either liquid hydrogen or liquid helium in the absorber body. The heat load that can be removed from the absorber with liquid hydrogen in the body can approach $200 \mathrm{~W}$, but only about $50 \mathrm{~W}$ of total heat can be removed from the same absorber filled with liquid helium.

\section{Can One Remove 1000 W from the Absorber by Natural Convection Cooling?}

The answer to the question above is probably yes, provided one has adequate heat transfer area to remove the heat and one can create enough head to circulate the hydrogen through the absorber. In order to remove $1000 \mathrm{~W}$ from hydrogen in an absorber, one must have an average heat transfer area of about 4 to 5 square meters. In order to remove $1000 \mathrm{~W}$ of heat from liquid helium in an absorber one needs a heat transfer area of about 14 square meters. It is unlikely that this amount of heat exchanger surface can be built into the absorber body in either type of absorber.

A separate heat exchanger located above the absorber body is needed if one wants to absorb more than about $150 \mathrm{~W}$ in the hydrogen in the absorber, with a reasonable helium flow. The warm hydrogen must leave the absorber at the top; while the cold hydrogen from the heat exchanger enters the absorber at the bottom. A flow schematic for such an absorber is shown in Figure 15. The distance between the top of the absorber and the center of the heat exchanger represents the extra head that is available to drive the free convection flow circuit. The heat exchanger must have as low a pressure drop as possible on the hydrogen side. The pipe bends must be designed so that the bend pressure drops are minimized. It is clear that pipe sizes will limit mass flow so the temperature differences in the hydrogen stream should be increased to about $1 \mathrm{~K}$. It is probable that with a proper design of the separate heat exchanger and extra length of pipe between the heat exchanger and the absorber, one can built a free convection cooled absorber capable of absorbing $1000 \mathrm{~W}$ in liquid hydrogen. 


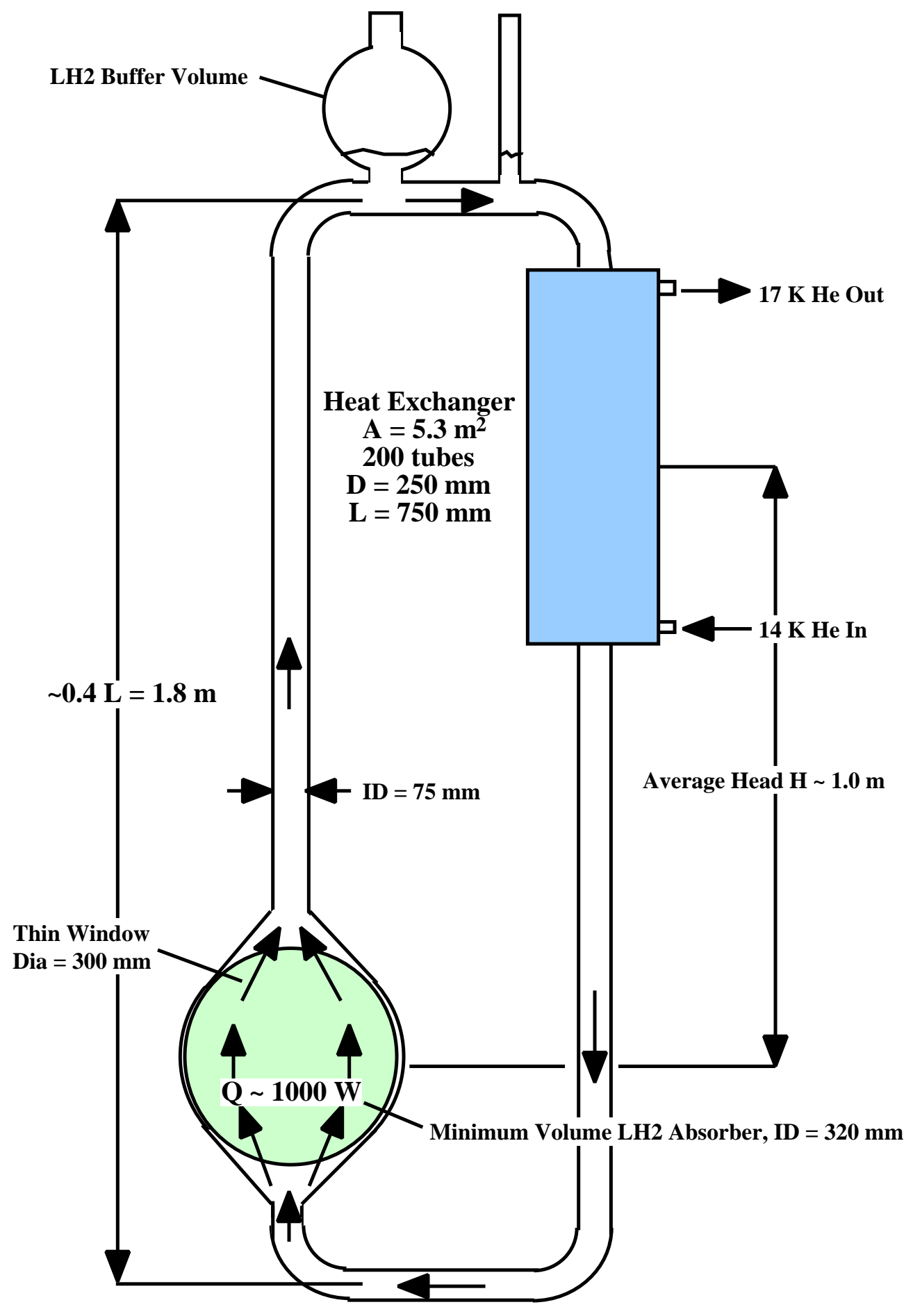

Figure 15. A Free Convection Cooled Hydrogen Absorber with a Separate Heat Exchanger to Cool the Liquid Hydrogen With adequate heat exchanger area, a larger pipe size, and a higher $\Delta \mathrm{T}$ in the hydrogen stream, $1 \mathrm{~kW}$ of heat can be removed. 
The heat exchanger shown in Figure 15, has 200 tubes with an ID $=9.55 \mathrm{~mm}$. These tubes carry the liquid hydrogen. The tube area on the hydrogen side is about $5.3 \mathrm{~m}^{2}$. The tube wall thickness is about $0.5 \mathrm{~mm}$, so the heat exchange area on the helium side is about $5.83 \mathrm{~m}^{2}$. The real issue is the size of the tube that carries the hydrogen to the heat exchanger from the absorber. Shown is a $75 \mathrm{~mm}$ tube, which has a cross-section area $=0.0044 \mathrm{~m}^{2}$. If one uses Equation 29 and one substitutes 2L (see Fig. 15) for $\mathrm{D}_{\mathrm{A}}$, one can come up with an approximate temperature drop $\left(\mathrm{T}_{\mathrm{h} 2}-\mathrm{T}_{\mathrm{h} 1}\right)$ for the hydrogen stream across the heat exchanger. The approximate hydrogen stream temperature rise in the absorber is $0.55 \mathrm{~K}$. In order to remove $\mathrm{Q}=1000 \mathrm{~W}$ from the absorber the mass flow $\mathrm{M}$ through the heat exchanger and the

absorber is about $0.0186 \mathrm{~kg} \mathrm{~s}^{-1}$. The density change across the absorber is about 1.1 percent, which is acceptable for muon cooling.

A free convection driven absorber and heat exchanger has no pump. Since there is no pump in the flow circuit there is no added heat that is put into the hydrogen from the pump work. It is also clear that adequate hydrogen flow to remove $1000 \mathrm{~W}$ of heat can be obtained from the buoyancy of the liquid hydrogen as it is heated. In my opinion, one should consider replacing the pumped hydrogen absorber proposed for the MUCOOL experiment with an absorber cooling system that uses free convection to circulate the liquid hydrogen. In the forced flow experiment proposed for MUCOOL, one should be careful and make sure that the hydrogen pump does not work against the natural convection forces.

\section{A Method for Creating Variable Length in a Hydrogen Absorber}

It has been proposed that the absorber length in MICE be variable. There are have been a number of proposals for varying the length of the absorber. Most of the proposals involve removing at least two of the absorber windows and adding (or subtracting) a section to the (from the) absorber body. Changing the length of the absorber by changing the absorber body presents a number of difficulties. These difficulties include: 1) Adding or subtracting an absorber body section changes the position of a least two of the absorber windows with respect to the beam low beta point. (If one wants to keep the absorber centered with respect to the low beta point, all four windows have to be removed.). 2) The position of the vacuum space between the hydrogen window and the safety window must be moved when the absorber length is changed. The connection of the vacuum space is to the external vacuum tank must also be moved. 3) The removal of a liquid hydrogen window or a safety window requires that a vacuum tight seal must be broken. This seal must be reestablished when the windows are reinstalled on the absorber. A removable hydrogen to vacuum seal and a removable seal on the safety window is not as reliable as welding the window to the absorber body or the aluminum extension between the safety window and the hydrogen window. 3) A change of the absorber length requires that the focusing magnet and absorber assembly be removed from the MICE cooling channel. Under the best of circumstances this can take a little under a month, and under the worst of circumstances this can take three months. Therefore, it is desirable to come up with a method of changing the absorber length without having to take the MICE cooling channel apart.

The method that is proposed here is to create a bubble of cold helium gas (at the same temperature as the liquid hydrogen) to displace liquid hydrogen from a space in the absorber. The density of the gas in this bubble would be from 3.2 to $4 \mathrm{~kg} \mathrm{~m}^{-3}$ depending on the temperature of the hydrogen in the 
absorber. If this bubble of helium is $150-\mathrm{mm}$ long in an absorber that is $350-\mathrm{mm}$ long, the effective length of the absorber would be reduced by 42 percent when the bubble is in place as compared to when bubble is not present. The multiple scattering per unit absorption length in the absorber due to the presence of the helium gas bubble will increased about 1.4 percent compared the same length of absorber with no helium bubble.

It is proposed that a Mylar bag be put into the absorber with thin walls that are say 25 to $50 \mu \mathrm{m}$ thick. This bag is filled with helium gas when the absorber length is reduced. When the pressure in the bag is greater than the pressure of the hydrogen, the bag will inflate with helium, thus displacing the liquid hydrogen in the absorber. When the pressure in the bag is less than that of the hydrogen in the absorber the bag will collapse allowing the hydrogen to occupy the full volume of the absorber. The presence of the bag will add about 50 to $100 \mu \mathrm{m}$ of plastic $\left(\rho=1.2 \mathrm{~g} \mathrm{~cm}^{-3}\right)$ to the absorption path. This plastic is equivalent to between 22 and $44 \mu \mathrm{m}$ of aluminum. In terms of multiple scattering this is equivalent to between 10 to $20 \mu \mathrm{m}$ of aluminum. The inflatable bag concept is illustrated in Figure 16.

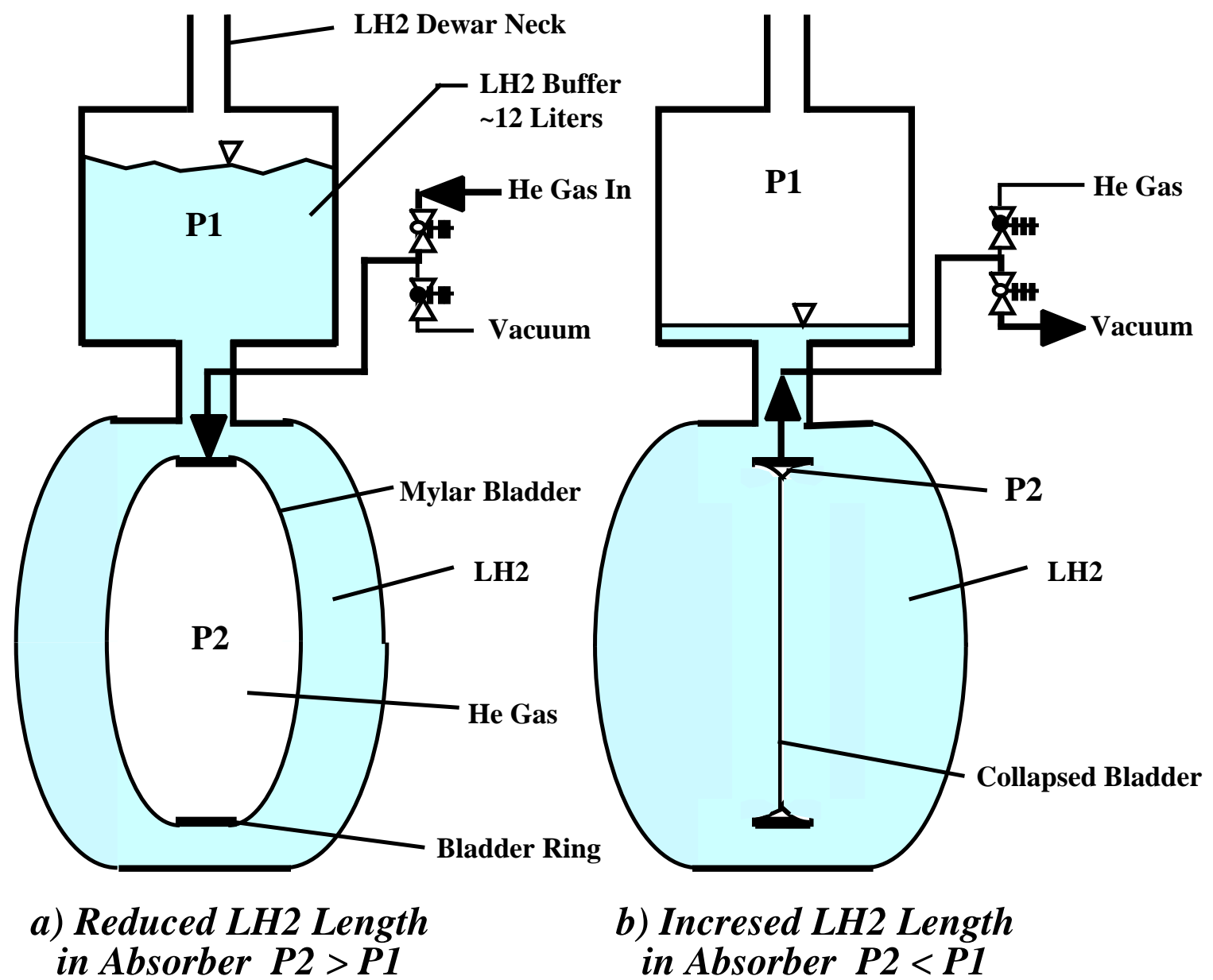

Figure 16. A Schematic Representation of One Method for Changing the Absorber Length Quickly by Displacing the Liquid Hydrogen with Helium Gas at the Same Temperature as the Liquid Hydrogen 
Figure 16 also shows a buffer volume that is attached to the absorber. When the Mylar bag is inflated the hydrogen displaced goes into the buffer volume. This buffer volume should be attached to the absorber through a thick walled 6061 or 1100 aluminum tube so that the buffer volume remains at the same temperature as the absorber case even when the bag is not inflated. The buffer volume will permit one to change the absorber length rapidly (in minutes) without boiling large amounts of liquid hydrogen. The buffer volume is not needed if the transition in the absorber path length is done slowly so that the extra hydrogen in the absorber can be boiled off and put in storage as a gas in a controlled way.

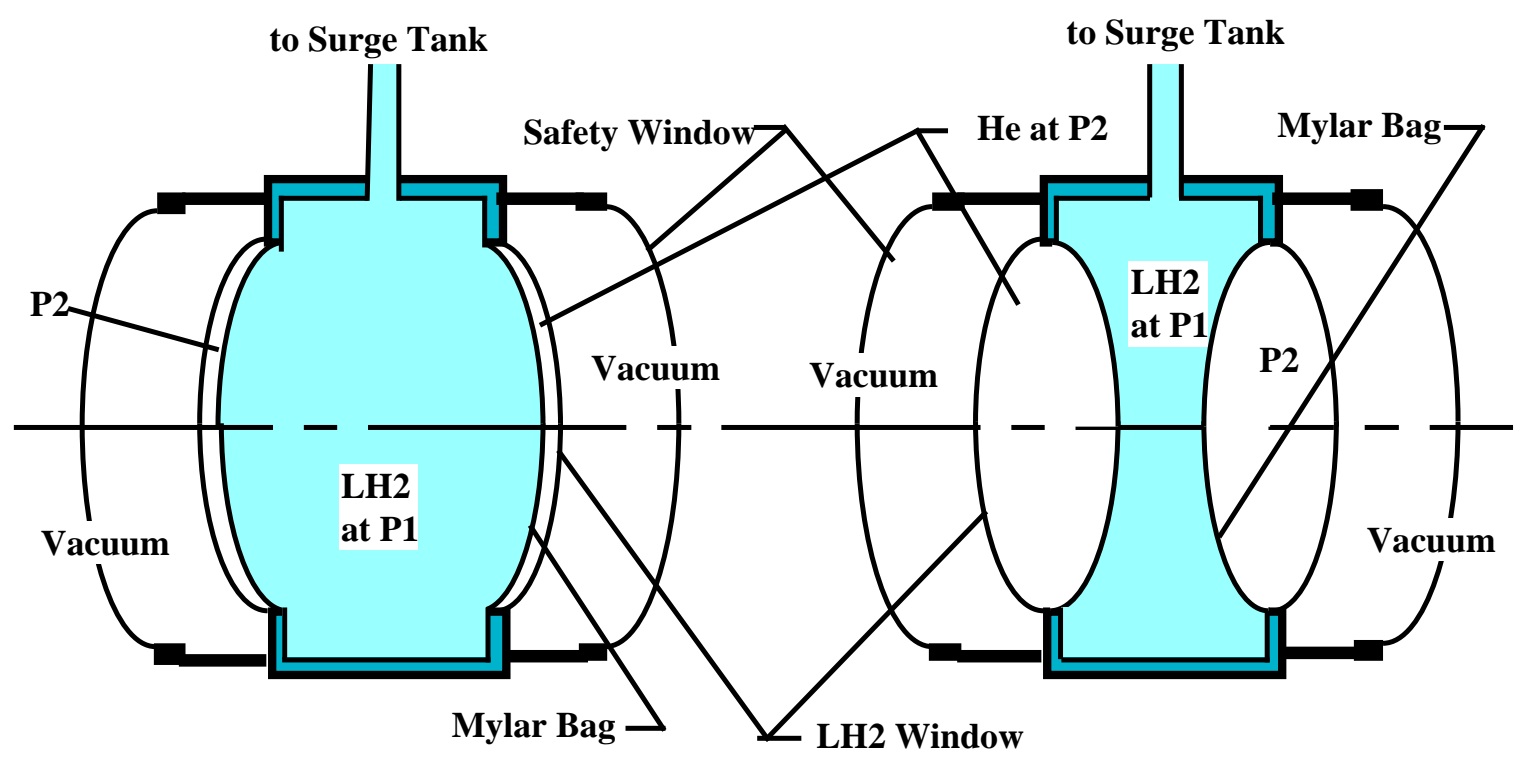

a) Full Volume LH2, P1 > P2

b) Reduced Volume LH2, P2 > P1

Figure 17. A Second Method for Reducing the Absorber Length by Displacing Liquid Hydrogen with Helium Gas

There are two approaches to using a bag or bags of helium to reduce the absorption path in a liquid hydrogen absorber. The first approach illustrated in Figure 16 is to place the helium bag in the center of the absorber. The liquid hydrogen that remains in the beam path is between the hydrogen windows and the bag. The center of the absorber is filled with helium gas when the absorber path length is reduced. The second approach for reducing the absorber path length is to put the helium next to the windows. The center of the absorber contains the liquid hydrogen. Figure 17 illustrates a second approach of using helium gas to displace the liquid hydrogen in the absorber. An advantage of the second approach is that the liquid hydrogen in the reduced absorber length state is in the lowest beta region of the beam (provided the absorber is centered in the focusing coils), which minimizes the effects of multi-scattering.

The author favors the first approach for use in MICE. The reasons for this are as follows: 1) The average beam beta changes less when the hydrogen is displaced at the center of the absorber. In an experiment such as MICE, it is desirable to minimize the beta change when the absorber length is changed. Changes in cooling due to absorber length change should not be confused with cooling changes due to a change in the beam beta in the absorber. 2) A single bag in the center is easier to 
fabricate. The bag can be inside the duct with the helium tube going up through the neck of the absorber. 3) Because the bag is at the center of the absorber inside the heat exchanger duct, the helium bag will not interfere with the function of the heat exchanger.

Figure 16 shows a buffer volume above the absorber; Figure 17 does not show a buffer volume. The buffer tank, is a displacement volume for the hydrogen in the absorber that is displaced when the Mylar bag fills with helium gas. For this to be effective, the buffer tank must be kept near $20 \mathrm{~K}$. The buffer volume is necessary, if one wants to make changes in the absorber volume over a short time (say one or two minutes). If one is willing to change the absorber length over a period of a couple of hours, the buffer volume is not needed. In order to simplify the MICE absorber, the buffer volume can be left out. It is unlikely that changes in absorber length have to be made in a few minutes.

Before leaving the topic of reducing the absorber length, it is useful to note that a bag filled with helium 4 (the normal isotope of helium) will not work for an absorber that is filled with liquid helium 4. It may be possible to use helium 3 (the helium isotope with two protons and neutron) as a displacement gas, because its boiling temperature is $3.13 \mathrm{~K}$. Because the pressure in the absorber is greater than 1.3 bar, the helium 3 will be at pressure and temperature above its critical point $\left(\mathrm{T}_{\mathrm{c}}=3.3 \mathrm{~K}, \mathrm{P}_{\mathrm{c}}=1.15\right.$ bar $)$. The problem of using helium 3 as a displacement gas in a liquid helium 4 absorber is the cost of the helium 3. Further study may be needed if it is really desirable to change the absorber length in a liquid helium absorber.

\section{Proposed Changes to the Absorber to Improve Integration with the Focusing Magnet}

The integration of the MICE absorber with the MICE focusing coils is discussed in the MICE magnet report . Integration of the absorber with the magnet affects the assembly and disassembly sequence of MICE. If the absorber design can be changed to make assembly and disassembly easier, the MICE experimental program will benefit because changing from liquid to solid absorbers during the time the experiment operates will be a realistic option.

The biggest change that one can make to improve the absorber design for MICE is to make it smaller both in length and in outside diameter. The argument for reducing the absorber length is that here is not enough RF acceleration to use three full sized level II study sized absorbers for two cells of level II study RF cavities that can not generate the acceleration gradient postulated in the level II study. Even if the MICE RF cavity cell could generate the acceleration gradient of a level II RF cavity cell, the length of the absorber should be less than $240 \mathrm{~mm}$, if the muon beam exiting the cooler is at the same energy as the muon beam entering the cooler. The argument for reducing the absorber diameter is based on the notion that the body diameter is dictated by the window diameter. The beam dynamics of MICE strongly suggests that safety window diameter should be no larger than $300 \mathrm{~mm}$. The hydrogen window diameter is less than the safety window diameter. This statement was also true for the level II study, but this fact is not reflected in the level II study report. Extra margin was put into the level II study absorber windows in hopes that beam acceptance of the RF cavities could be increased by making their beryllium windows larger. The case for making the RF cavity window larger in the level II study was tenuous at best, and this certainly will not happen in MICE. 
Reducing the absorber diameter and length will reduce the amount of liquid hydrogen in the absorber by nearly fifty percent. This is going the correct direction when it comes to liquid hydrogen safety. Making the inside diameter of the absorber smaller means that the outer diameter of the absorber can also be reduced. The stay clear diameter of the focusing magnet is $490 \mathrm{~mm}$. If one reduces the diameter of both the hydrogen window and the safety window to $300 \mathrm{~mm}$, there is space to take hydrogen, helium, and vacuum pipes out of the absorber at one end of the absorber and route them along the absorber length. The absorber pipes and the absorber body must fit in a space that is no more than $475 \mathrm{~mm}$ in diameter. Pipes that connect to the absorber inside the magnet bore that are routed parallel to the solenoid axis do not penetrate the support structure of the focusing solenoids. Hence, the focusing solenoids do not have to be assembled around the hydrogen absorber. An illustration of this concept is shown in Figure 18.

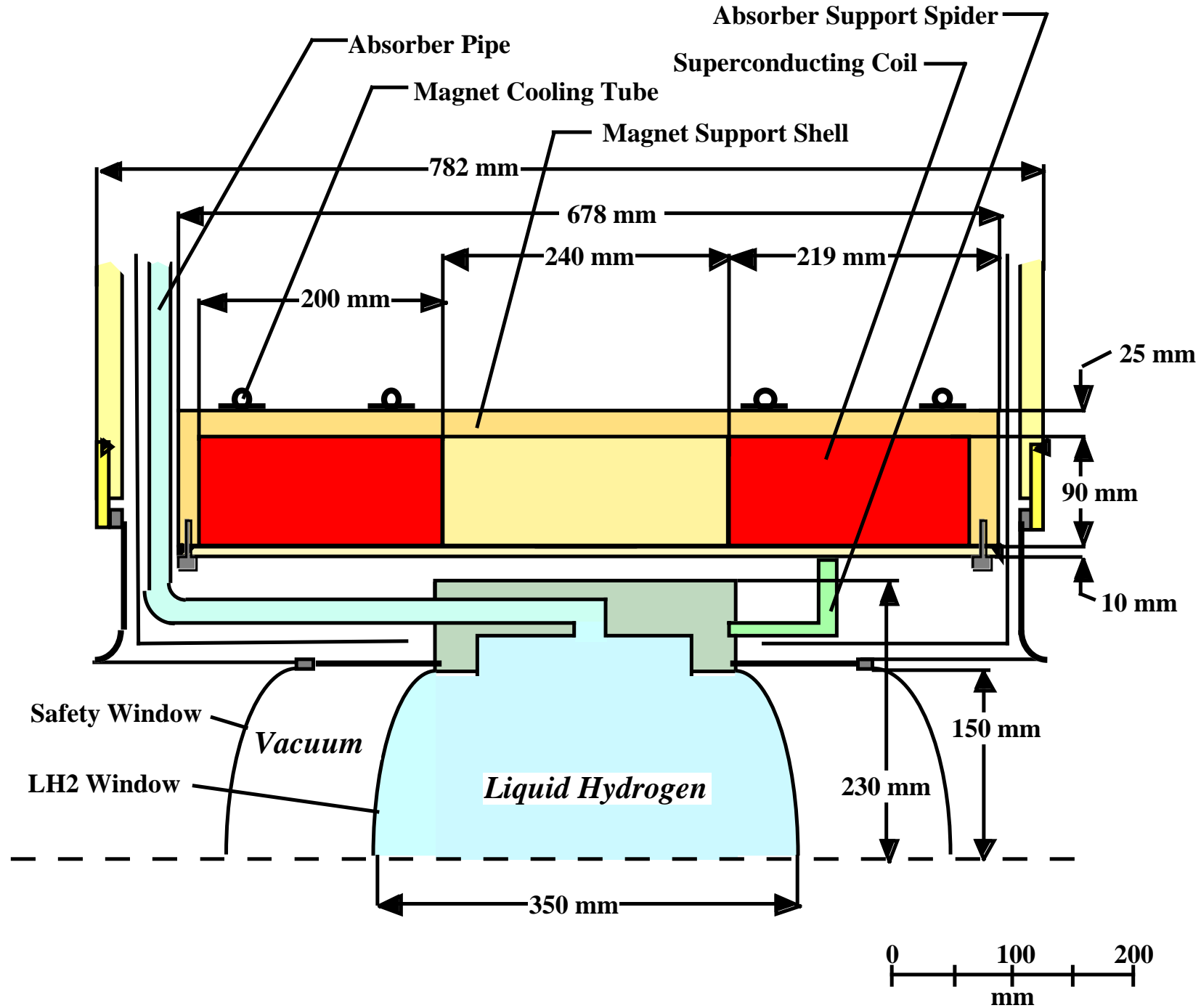

Figure 18. An Absorber that can slide into the Focusing Coil from One End. Note: there is support spider shown at one end of the absorber. A support spider will also be at the pipe end of the absorber, but not where the feed pipes are located. 
The implication of being able to route the absorber pipes parallel to the absorber axis means that one can design an absorber that can be removed from the focusing magnet without disassembling the focusing coils or removing the magnet from its cold mass support system. This means that it may be possible to remove the whole liquid hydrogen absorber from the superconducting magnet as quickly as one would remove the windows in the MICE absorber design currently being proposed. Safety will be enhanced because the hydrogen windows and safety windows will be welded to the absorber body. Another implication of reducing the absorber window size is that the thin windows can be made thinner.

In order to bring the pipes out of the absorber, the pipes have to go past the one end of the focusing magnet. In order to do this the focusing magnet must be shifted lengthwise in its cryostat so that there is room for the absorber piping at one end of the magnet. It clear that a removable absorber is very desirable because this allows one to replace the liquid absorber with a solid absorber in the same time it would take to replace an absorber window in the current MICE configuration.

The downside of reducing the absorber size is the fact that the heat exchanger area in the absorber is reduced. A reduction of the absorber diameter of 10 percent and a reduction of the absorber length from $350 \mathrm{~mm}$ to $240 \mathrm{~mm}$ will result in a reduction of the heat exchanger area by a factor of two. The heat coming into the absorber by thermal conduction and radiation should be reduced by about 20 percent because the absorber is smaller. When one looks at the heat loads that will actually be going into the MICE absorbers from all sources, a design heat load of $50 \mathrm{~W}$ for the smaller absorber should be adequate. By increasing the mass flow of $14 \mathrm{~K}$ helium gas through the absorber to $9-\mathrm{g} \mathrm{s}^{-1}$, one should be able to remove over $100 \mathrm{~W}$ from the reduced size absorber even though its heat exchanger area has been reduced by a factor of two.

\section{Some Concluding Comments}

In conclusion, the following general comments can be made concerning the liquid hydrogen absorber for MICE: 1) The MICE absorber can be designed so that the heat into the absorber by conduction and radiation is taken to the absorber body without passing into the absorber fluid. 2) The safety window of the liquid hydrogen absorber will in all cases be at a temperature above $55 \mathrm{~K}$. This means that oxygen from the RF cavity vacuum space will not freeze on the window or any part of the absorber that is exposed to that vacuum space. This means that the RF vacuum chamber does not have to be blanketed with an inert gas such as argon. Oxygen deposition on the superconducting coils and the $20 \mathrm{~K}$ parts of the absorber from small leaks in the magnet and absorber vacuum vessel may still be an issue. The magnet and absorber vacuum vessel may have to be blanketed with an inert gas.

The following comments can be made concerning the heat exchanger for natural convection cooling of the MICE absorber: 3) The helium that is cooling the absorber must flow up the walls of the absorber from the bottom to the top. The hydrogen will flow down the wall driven by natural convection forming a counter-flow heat exchanger. The counter flow heat exchanger is more efficient than a parallel flow heat exchanger or a combined flow heat exchanger (see Figures 8 and 9). The author recommends that the flow next to the wall be ducted. The duct should be 20 to $30 \mathrm{~mm}$ from the wall. The wall that forms the heat exchanger should be finned on both sides. 4) The mass flow of the fluid on the natural convection side of the absorber varies as the square root of the heat to be transferred. 
5) The temperature rise in the absorber fluid varies as the square root of the heat to be transferred. These relationships are independent of the fluid in the natural convection flow system. 6) At low helium mass flows, the helium side of the heat exchanger dominates the heat exchanger $U$ factor. At high helium mass flows, the hydrogen side controls the heat exchanger $U$ factor. 7) Conduction through the aluminum heat exchanger walls is a small part of the $U$ factor.

The following conclusion are drawn from the heat transfer calculations of the MICE absorber with liquid hydrogen or liquid helium as an absorption fluid: 8) The standard 350-mm long liquid hydrogen absorber for MICE can be cooled by natural convection from the absorber walls at cooling rates greater than $100 \mathrm{~W}$ when helium gas enters the absorber cooling channel at $14 \mathrm{~K}$. Since the helium gas entrance temperature is $14 \mathrm{~K}$, hydrogen will not freeze in the absorber. The flow rate of the $14 \mathrm{~K}$ helium can be controlled using the pressure in the hydrogen absorber as a control variable. The liquid hydrogen absorber should not operate at a pressure above $0.1013 \mathrm{MPa}$ (one atmosphere) or a temperature above $20.3 \mathrm{~K}$ The temperature range from $14 \mathrm{~K}$ to $20.3 \mathrm{~K}$ defines the heat transfer in the hydrogen absorber system. 9) Natural convection cooling of the standard absorber, with liquid helium at 2 bar in the absorber, can be done for total heat loads in excess of $45 \mathrm{~W}$, provided the conduction and radiation heat loads are conducted directly to the two phase helium at $4.3 \mathrm{~K}$ that is cooling the absorber. The subcooled helium side controls the $U$ factor of the heat exchanger in the helium absorber. 10) The gross density change of the fluid in the absorber as it is heated by the beam and a heater at the bottom of the absorber is small (less that 1.2 percent for either fluid). Density changes in some parts of the absorber where fluid is stagnant locally may be much larger.

Natural convection cooling can be extended to liquid hydrogen absorbers with heat loads up to or even above $1 \mathrm{~kW}$, provided the heat exchanger is separated from the absorber. The heat exchanger must be adequately sized and the pipes carrying the absorber fluid must be large enough to not cause a temperature rise above $1 \mathrm{~K}$ in the hydrogen. Circulation using natural convection makes sense even for the MUCOOL experiment. Since large heat fluxes into a liquid helium absorber mean large refrigeration loads at $4.3 \mathrm{~K}$, a large liquid helium absorber would not be considered over a solid lithium hydride or lithium absorber, which have similar multiple scattering coefficients. The topic of solid absorbers will be dealt with in another note.

The thickness of a hydrogen absorber can be reduced by displacing the hydrogen with a bag of helium gas at liquid hydrogen temperature. This method can be used to make absorber length changes up to fifty percent. If a change in absorber length must be made quickly (in a few minutes), a buffer volume for the hydrogen displaced must be available. This buffer volume must be kept at 20 to $25 \mathrm{~K}$ when the absorber length is maximized. If it is tolerable to change the absorber length in say two hours, a liquid hydrogen buffer is not needed. It is better to use a single helium bag in the center of the absorber rather than two helium bags next to the window to change the absorber length. The percentage change of average beam beta, as the absorber length is changed, is lower for the single bag case.

Reducing the size of the MICE absorber to fit the actual conditions of the experiment is probably a good thing to do. The absorber length should be reduced to reflect the fact that the RF cavity system can not accelerate the muons enough to make up for the loss of muon momentum in the absorbers. Reducing the amount of liquid hydrogen in the absorber is probably also a good thing to do. With less liquid hydrogen in the absorber the safety sphere volume can be reduced. The size of the pipes leading 
to the safety sphere can also be reduced. Absorber size, the size of piping, and the size of the safety sphere will have a direct bearing on the cost of the absorber portion of the experiment. Reducing absorber size has other positive effects on MICE, because absorber physical size can have a direct effect on the down time needed to make a change in the absorber configuration.

It is desirable to make an absorber that can slide into the superconducting magnet without requiring that the coils be removed from their cold mass supports or that the focusing coil pair be disassembled. An absorber that can slide into the magnet from the end can have pipes that disconnect well away from the absorber body. If the absorber can be removed from the magnet easily, there is no need to make either the hydrogen windows and or the safety windows removable. The absorber body, the piping leading into the absorber body and the absorber windows can be a welded pre-vacuum leak checked and pre-tested unit. This has a profound effect on the quality control and safety of the experiment. A reduction of the absorber size to the extent that it can be slid out of the magnet as a preassembled unit will have an effect on the heat transfer from the absorber fluid to the cooling helium. The heat exchanger in the reduced size absorber can still remove $100 \mathrm{~W}$ of heat provided the mass flow of $14 \mathrm{~K}$ helium is increased. Since the actual heat loads into the absorber are only about $40 \mathrm{~W}$, there is still plenty of design margin in the heat exchangers.

\section{Acknowledgements}

The author acknowledges discussions with Wing Lau of Oxford University concerning absorber heat flow. The author also acknowledges the work of Dan Kaplan and Ed Black of the Illinois Institute of Technology concerning absorber design and safety issues. This work was supported by the Office of Science, United States Department of Energy under DOE contract number DE-AC03-76SF00098

\section{References}

[1] H. C. Hottle, Chapter 2 of Heat Transmission (by W. C. McAdams), $3^{\text {rd }}$ Edition, McGraw Hill Book Company, New York 1954

[2] A. K. Oppenheim, “The Network Method of Radiation Analysis,” ASME Paper 54-A75 (1954)

[3] Frank Kreith, Principles of Heat Transfer, International Text Book Co., Scranton PA, (1958)

[4] L. M. Milne-Thomson, Theoretical Hydrodynamics, $4^{\text {th }}$ Edition, MacMillan Company, New York (1960)

[5] Hermann Schlichting, (translated by J. Kestin), Boundary Layer Theory, $4^{\text {th }}$ Edition, McGraw Hill Book Company, New York (1960) This reference was published as Grenzschicht-Theorie, by G. Braun GmbH, Karlsruhe, (1951)

[6] John K. Vennard, Elementary Fluid Mechanics, $3^{\text {rd }}$ Edition, John Wiley and Sons Incorporated, New York, (1959)

[7] Victor J. Johnson Ed., A Compendium of the Properties of Materials at Cryogenic Temperature, Pergamon Press, New York (1961) 


\section{DISCLAIMER}

This document was prepared as an account of work sponsored by the United States Government.

While this document is believed to contain correct information, neither the United States

Government nor any agency thereof, nor The Regents of the University of California, nor any of their employees, makes any warranty, express or implied, or assumes any legal responsibility for the accuracy, completeness, or usefulness of any information, apparatus, product, or process disclosed, or represents that its use would not infringe privately owned rights. Reference herein to any specific commercial product, process, or service by its trade name, trademark, manufacturer, or otherwise, does not necessarily constitute or imply its endorsement, recommendation, or favoring by the United States Government or any agency thereof, or The Regents of the University of California. The views and opinions of authors expressed herein do not necessarily state or reflect those of the United States Government or any agency thereof, or The Regents of the University of California.

Ernest Orlando Lawrence Berkeley National Laboratory is an equal opportunity employer. 